\title{
Frequency-Modulation Control of a DC/DC Current-Source Parallel-Resonant Converter
}

\author{
Mohammad Moradi Ghahderijani, Miguel Castilla, Arash Momeneh, Jaume Tomas Miret, Member, IEEE, \\ and Luis Garcia de Vicuña
}

\begin{abstract}
This paper proposes a frequency-modulation control scheme for a dc/dc current-source parallel-resonant converter with two possible configurations. The basic configuration comprises an external voltage loop, an internal current loop, and a frequency modulator: the voltage loop is responsible for regulating the output voltage, the current loop makes the system controllable and limits the input current, and the modulator provides robustness against variations in resonant component values. The enhanced configuration introduces the output inductor current as a feed-forward term and clearly improves the transient response to fast load changes. The theoretical design of these control schemes is performed systematically by first deriving their small-signal models and second using Bode diagram analysis. The actual performance of the proposed control schemes is experimentally validated by testing on a laboratory prototype.
\end{abstract}

Index Terms-Control design, control systems, dc-dc power converters, frequency modulation, resonant converters.

\section{INTRODUCTION}

S INCE the emergence of the resonant technology, major $\checkmark$ research efforts have been conducted to apply the enhanced features of resonant converters to practical applications [1]-[8]. Induction heating [1], electric vehicle [2], lighting system [3], robotic industry [4], [5], and contactless energy-transfer system [6]-[8] are just a short list of examples. DC-DC conversion category is another industry example of great importance for these converters. Battery charging, electronic air purifiers, and switching power supplies are among these applications, ranging from low to high power [9]-[15]. A great interest has been taken in these converters due to their generated high frequency sinusoidal waveforms, reducing the electromagnetic interference and switching losses [16]. The control strategy has

Manuscript received September 2, 2016; revised December 5, 2016; accepted February 16, 2017. This work was supported in part by ELAC2014/ESE0034 from the European Union and its linked Spanish National Project PCIN-2015-001, in part by the Ministry of Economy and Competitiveness of Spain, and in part by the European Regional Development Fund (FEDER) under Project ENE2015-64087-C2-1-R.

The authors are with the Department of Electronic Engineering, Technical University of Catalonia, 08800 Barcelona, Spain (e-mail: mohammad.moradi.ghahderijani@upc.edu; miquel.castilla@upc.edu; arash.momenh@yahoo.com; jmiret@eel.upc.edu; vicuna@eel.upc. edu).

Color versions of one or more of the figures in this paper are available online at http://ieeexplore.ieee.org.

Digital Object Identifier 10.1109/TIE.2017.2677321 been one of the challenging research keys in this field. For voltage-source series-resonant converters, many control strategies have been analyzed and investigated [17]-[23], turning this into a mature technology nowadays. However, compared to the series-resonant topologies, parallel-resonant converters absorb a continuous smooth current from the input source, offering low current stress to switches [24]. Likewise, the reactive power circulates inside the parallel resonant tank and only the active power is supplied through the switches. This feature provides the capability of generating high current and voltage levels by using low VA-rated switches, reducing conduction losses. In addition, these converters provide more facilities such as short-circuited protection and paralleling capabilities. For the reasons outlined above, the research on the current-source parallel-resonant converters (CSPRC) has recently attracted more interest [25]-[31]. In particular, in [25], a current source topology has been proposed to supply a multireceiver inductive contactless energy transfer system. In this topology, a buck converter has been utilized to obtain an input current source with constant amplitude, supplying the resonant inverter. In [26], a simple modulation technique has been proposed for this type of converter and then applied to an induction heating system [27]. This method is then further developed in [28]. In [29], the modulation technique has been applied to an inductive contactless energy transfer system. A delta-sigma modulator is also applied to a class-D CSPRC in [30]. In all these works, the current-source converters operate in open loop and thus they exhibit a high sensitivity to external disturbances and parameter variations. In [31], a closed-loop control scheme with amplitude modulation has been presented for a dc/dc CSPRC. A robust behavior against load changes was demonstrated in this study by simulation results; however, some drawbacks inherent to the amplitude modulation limit its practical use.

The aim of this paper is to introduce a control scheme for the $\mathrm{dc} / \mathrm{dc}$ class-D CSPRC intended for switching power supplies. The control scheme has two possible configurations. The basic configuration is responsible for both regulating the output voltage and providing zero voltage switching (ZVS) conditions. A cascaded control scheme is proposed to this end, including an external voltage loop and an internal current loop. ZVS conditions are guaranteed by driving the switches with a robust frequency modulation technique. In addition, an enhanced control configuration is presented in this paper in order to further improve the load transient response of the basic configuration. The design of the control schemes is based on two steps. First, 


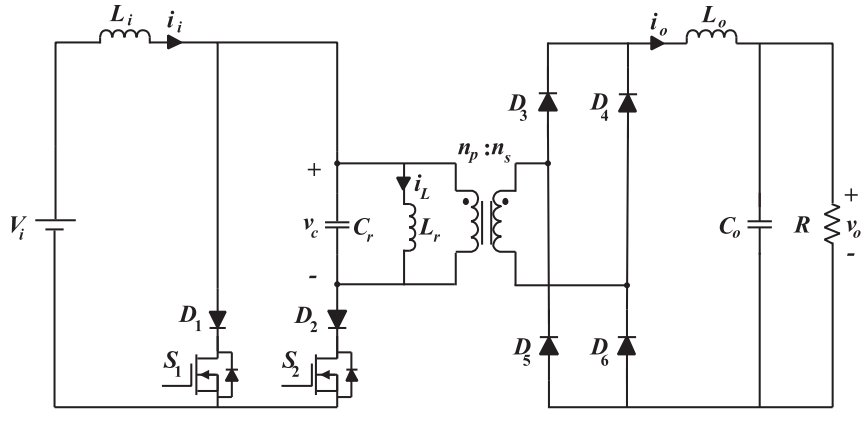

Fig. 1. Power circuit of the class-D CSPRC.

a dynamic model of the open-loop CSPRC is obtained. Afterward, the small-signal characteristics of the obtained averaged model are derived. Second, the dynamic model for the closedloop system is formulated and a systematic procedure to design the control gains is presented.

The theoretical contributions of this paper are: the large-signal model of the CSPRC operating with frequency modulation; 2) its small-signal model; 3 ) the control scheme, including the basic and enhanced control-loop configurations and the frequency modulator (FM); and 4) the systematic design procedure for deriving the control gains. As far as authors know, there are no previous studies exploring these four topics together or separately for the considered resonant topology.

This paper is structured as follows. Section II derives the large-signal model of the class-D CSPRC and its averaged smallsignal model. Section III introduces the basic and enhanced control configurations, including the FM. Section IV presents the design process of the proposed control scheme intended for $\mathrm{dc} / \mathrm{dc}$ applications. Section V verifies the theoretical contributions by selected experimental results in a laboratory prototype. Finally, Section VI gives the conclusions.

\section{Dynamic Modeling OF THE CLASS-D CSPRC}

Fig. 1 shows the power circuit of the dc/dc class-D CSPRC. The class-D resonant inverter includes an input inductor $\left(L_{i}\right)$, a second-order parallel-resonant tank $\left(L_{r}\right.$ and $\left.C_{r}\right)$ and a highfrequency transformer with winding turns ratio $n_{p}: n_{s}$. The resonant tank is loaded through a full-bridge diode rectifier and a second-order low-pass filter $\left(L_{o}\right.$ and $C_{o}$ ) to get a dc output voltage. The operation principle of this converter using frequency modulation was presented in detail in [24], and thus it is not repeated here.

The first contribution of this paper is the development of an adequate dynamic description of the class-D CSPRC converter for dc switching power supply applications. This model is essential for the control design process. Below is a step-by-step derivation of the dynamic model.

\section{A. State-Space Model}

The assumptions to derive the model are: 1) the components are ideal and 2) the circuit is driven by frequency modulation. In this case, the control input is the angular switching frequency $\omega_{s}$.
This variable will be provided by the control system in order to reach the control objectives (i.e., output voltage regulation and operation under ZVS conditions). Under these assumptions and taking into account the equivalent circuits of the converter presented in [24], the differential state-space equations can be expressed as follows:

$$
\begin{aligned}
\frac{d i_{i}}{d t} & =\frac{1}{L_{i}}\left[V_{i}-\left(\frac{1+\operatorname{sgn}\left(\sin \omega_{s} t\right)}{2}\right) v_{c}\right] \\
\frac{d v_{c}}{d t} & =\frac{1}{C_{r}}\left[\left(\frac{1+\operatorname{sgn}\left(\sin \omega_{s} t\right)}{2}\right) i_{i}-i_{L}-\frac{n_{s}}{n_{p}} \operatorname{sgn}\left(v_{c}\right) i_{o}\right]
\end{aligned}
$$

$\frac{d i_{L}}{d t}=\frac{1}{L_{r}} v_{c}$

$\frac{d i_{o}}{d t}=\frac{1}{L_{o}}\left[\frac{n_{s}}{n_{p}}\left|v_{c}\right|-v_{o}\right]$

$\frac{d v_{o}}{d t}=\frac{1}{C_{o}}\left[i_{o}-\frac{v_{o}}{R}\right]$

where $i_{i}$ stands for the input current variable, $v_{c}$ and $i_{L}$ are the resonant state variables, and $v_{o}$ and $i_{o}$ are the output filter state variables. According to [32], the state-space variables can be divided in two subgroups: fast and slow variables. The resonant state variables are fast variables and evolve the following sinusoidal waveforms. Input current and output voltage and current are slow variables. They evolve slowly compared to the dynamics of resonant waveforms.

\section{B. Averaged Modeling of the Resonant State Variables}

The averaged method presented in [32] is used here to obtain 139 a proper dynamic model. In this method, the resonant state variables are approximated as sinusoidal waveforms including slow time-varying amplitudes and phases, defined as

$$
\begin{aligned}
& v_{c}=V_{c} \sin \left(\omega_{s} t-\alpha\right) \\
& i_{L}=I_{L} \sin \left(\omega_{s} t-\beta\right)
\end{aligned}
$$

where $V_{c}$ and $I_{L}$ are the peak values of the resonant state vari- 143 ables, and $\alpha$ and $\beta$ are the initial phases. These variables are 144 then inserted into (2) and (3). By applying harmonic lineariza- 145 tion and harmonic balance to the resulting model, the following 146 equation is derived:

$$
\frac{d \bar{v}_{c}}{d t}=\frac{1}{C_{\mathrm{eq}}}\left[\frac{m}{2} \overline{i_{i}}-\frac{n_{s}}{n_{p}} \bar{i}_{o}\right]
$$

where the symbol-denotes averaged value over a half-switching 148 cycle, and the equivalent capacitor $C_{\mathrm{eq}}$ and the new variable $m \quad 149$ can be expressed as

$$
\begin{aligned}
C_{\mathrm{eq}} & =\pi^{2} C_{r} / 8 \\
m & =\sqrt{1-\left[\frac{\pi^{2} Q}{4 R} \frac{\bar{v}_{c}}{\overline{i_{i}}}\left(\frac{\omega_{s}}{\omega_{o}}-\frac{\omega_{o}}{\omega_{s}}\right)\right]^{2}} .
\end{aligned}
$$

Note that $m$ is a variable that contains information about 151 the system state in an averaged sense (through the variables 152 $\bar{v}_{c}$ and $\bar{i}_{i}$ ) and the control action $\omega_{s}$. It is used here simply 153 125 126 127 128 129 136 137 141 142

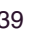

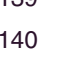


to compact the final expressions of the models. In (10), the variables $Q$ and $\omega_{o}$ represent the quality factor and angular resonant frequency of the resonant tank. In addition, $Z_{o}$ is the characteristic impedance. These variables are defined as

$$
\begin{aligned}
Q & =R / Z_{o} \\
\omega_{o} & =1 / \sqrt{L_{r} C_{r}} \\
Z_{o} & =\sqrt{L_{r} / C_{r}} .
\end{aligned}
$$

Further details on model derivation can be found in [33][35], where the averaged models of other resonant topologies have been derived. Note that, in this case, the resonant tank is described in an averaged sense because only one differential equation (8) models the dynamics of the averaged resonant capacitor voltage. This equation contains all the necessary information to reproduce the transient and steady-state behavior of the resonant tank in an averaged sense. Also, note that this equation is nonlinear.

\section{Averaged Modeling of Slow Variables}

The averaged dynamics of the slow variables, including the input and output state variables, are derived by using the timevarying averaging over a half-switching cycle, resulting in

$$
\begin{aligned}
& \frac{d \overline{i_{i}}}{d t}=\frac{1}{L_{i}} \cdot\left[V_{i}-\frac{m}{2} \bar{v}_{c}\right] \\
& \frac{d \bar{i}_{o}}{d t}=\frac{1}{L_{o}}\left[\frac{n_{s}}{n_{p}} \bar{v}_{c}-\bar{v}_{o}\right] \\
& \frac{d \bar{v}_{o}}{d t}=\frac{1}{C_{o}} \cdot\left[\bar{i}_{o}-\frac{\bar{v}_{o}}{R}\right] .
\end{aligned}
$$

Therefore, the complete averaged large-signal model of the class-D CSPRC is expressed by (8) and (14)-(16).

As far as authors know, the large signal model for the frequency-modulated CSPRC has not been previously studied. Hence, this model constitutes the first contribution of this paper. The accuracy of this model is validated in Section II-E by selected simulation results.

\section{Equilibrium Point}

In steady-state conditions, all the averaged variables reach their equilibrium point. By considering $d \overline{\mathrm{i}_{i}} / d t=0, d \overline{v_{c}} / d t=$ $0, d \overline{\mathrm{i}_{o}} / d t=0$, and $d \overline{v_{o}} / d t=0$, the equilibrium point of the model (8) and (14)-(16) can be expressed as

$$
\begin{aligned}
I_{i} & =\frac{V_{0}^{2}}{R V_{i}} \\
V_{c} & =\frac{2 V_{i}}{M} \\
I_{o} & =\frac{V_{o}}{R} \\
V_{o} & =\frac{n_{s}}{n_{p}} \frac{2 V_{i}}{M}
\end{aligned}
$$

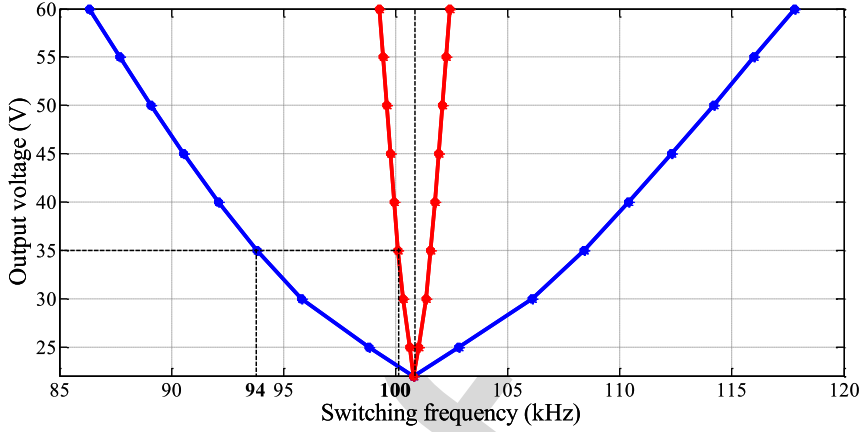

Fig. 2. Output voltage as a function of the switching frequency (FL in blue and $10 \%$ of FL in red).

TABLE I

VALUes of THE POWER COMPONENTS

\begin{tabular}{llc}
\hline \hline Symbol & \multicolumn{1}{c}{ Quantity } & Value \\
\hline$V_{i}$ & Input voltage & $12 \mathrm{~V}$ \\
$L_{i}$ & Input filter inductor & $300 \mu \mathrm{H}$ \\
$C_{r}$ & Resonant capacitor & $470 \mathrm{nF}$ \\
$L_{r}$ & Resonant inductor & $5.3 \mu \mathrm{H}$ \\
$n_{p}: n_{s}$ & Transformer turns ratio & $1: 1$ \\
$L_{o}$ & Output filter inductor & $100 \mu \mathrm{H}$ \\
$C_{o}$ & Output filter capacitor & $470 \mu \mathrm{F}$ \\
$V_{o}$ & Output voltage & $35 \mathrm{~V}$ \\
$R$ & Full-load resistor & $20 \Omega$ \\
\hline \hline
\end{tabular}

where $M$ is the steady-state value of $m$ (i.e., the equilibrium 183 point of $m$ ), which can be written as

$$
\frac{1}{M}=\sqrt{1+\left[\frac{\pi^{2}}{8} Q\left(\frac{n_{s}}{n_{p}}\right)^{2}\left(\frac{\omega_{s}}{\omega_{o}}-\frac{\omega_{o}}{\omega_{s}}\right)\right]^{2}} .
$$

Note that the equilibrium point depends on the control input 185 $\omega_{s}$, the resonant circuit parameters, the input voltage, and the 186 load.

The output voltage in steady state can be easily determined from (20) and (21). Fig. 2 depicts this voltage as a function of the switching frequency for two load conditions: full load (FL) in blue and $10 \%$ of FL in red. The nominal values of the power components listed in Table I are used to draw the figure. Note that the output voltage can be maintained constant in steady state by adjusting conveniently the switching frequency. In fact, Fig. 2 also shows the theoretical values of the switching frequency that provides the nominal output voltage for the two considered load conditions.

\section{E. Validation of the Averaged Large-Signal Model}

The validity of the derived large-signal model expressed in (8) and (14)-(16) is evaluated by comparing selected simulation results with those obtained by the state-space model expressed in (1)-(5). Both models are implemented in MATLAB-Simulink, and the obtained results are shown in Fig. 3. Two different switching frequencies are considered to validate the averaged model in different operating points. During the first interval, the switching frequency is fixed at $91 \mathrm{kHz}$. At $t=10 \mathrm{~ms}$, the 


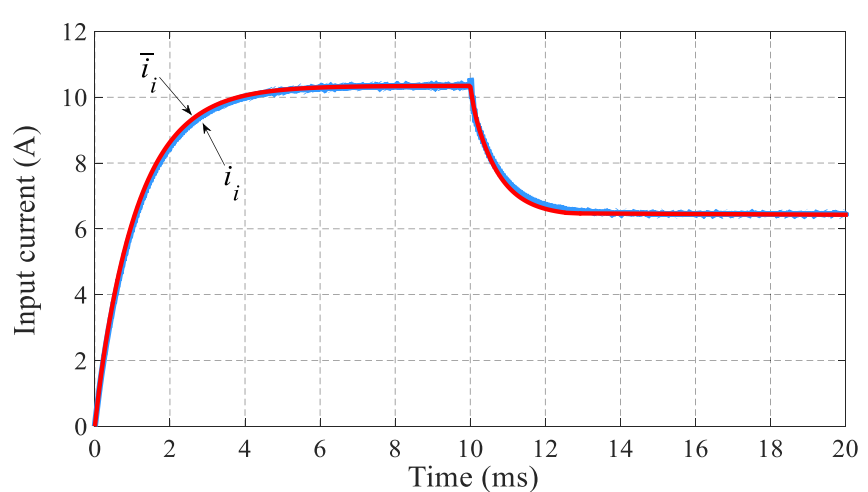

(a)

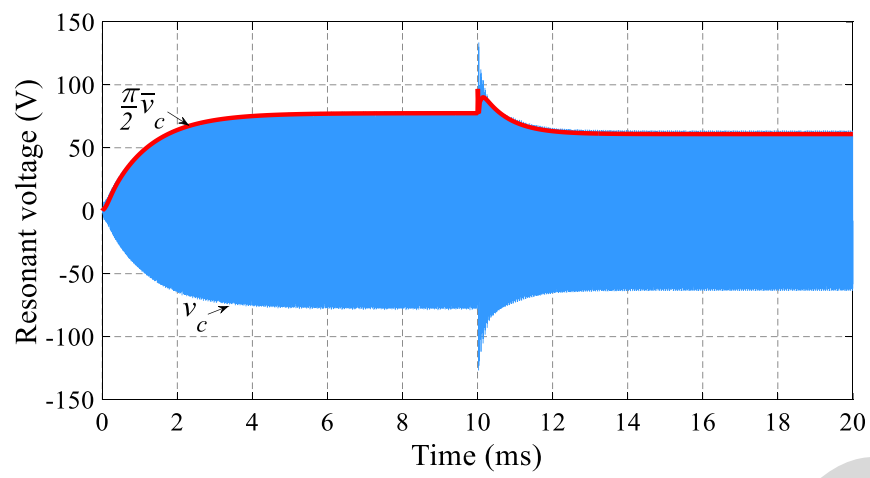

(b)

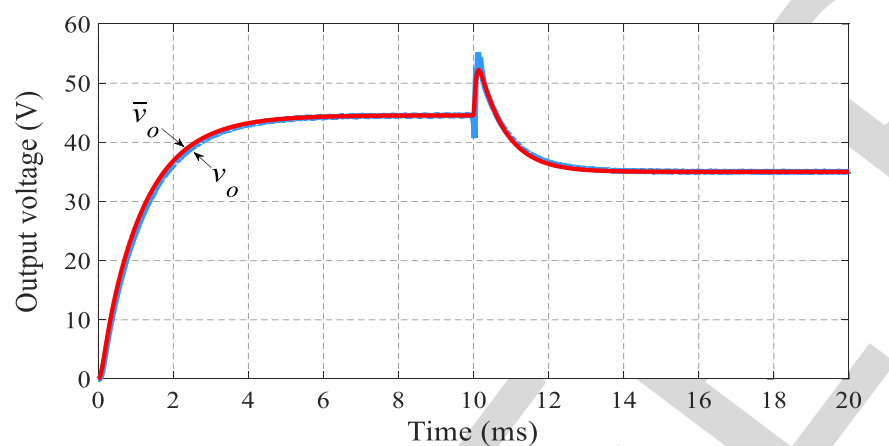

(c)

Fig. 3. Comparison of waveforms generated by the state-space model and the averaged large-signal model for two different switching frequencies $(0<t<10 \mathrm{~ms}: 91 \mathrm{kHz}, 10 \mathrm{~ms}<t<20 \mathrm{~ms}: 94 \mathrm{kHz})$ and FL condition: (a) input current, (b) resonant capacitor voltage, and (c) output voltage. switching frequency is changed to $94 \mathrm{kHz}$. This frequency is maintained to the end of the test. The results show good agreement between the models, although some small differences appear when the switching frequency is abruptly changed at $t=10 \mathrm{~ms}$. These mismatches are clearly caused by the assumptions made in the large-signal model derivation. However, for control design purposes, the observed high-frequency transients are not important due to the limited control bandwidth (BW).

\section{F. Small-Signal Model}

The small-signal model of the converter is derived by following the conventional approach based on perturbing and linearizing the large-signal model [36]. The systematic procedure is presented below. First, the state variables are decomposed in 220

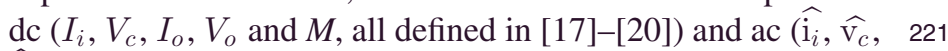
$\widehat{\mathrm{i}_{o}}, \widehat{\mathrm{v}_{O}}$, and $\widehat{m}$ ) terms, given as follows:

$$
\begin{aligned}
& \bar{i}_{i}=I_{i}+\widehat{i_{i}} \\
& \bar{v}_{c}=V_{c}+\widehat{v_{c}} \\
& \overline{i_{o}}=I_{o}+{\widehat{i_{o}}} \\
& \bar{v}_{o}=V_{o}+\widehat{v_{o}} \\
& m=M+\hat{m} .
\end{aligned}
$$

Second, the amplitudes of the ac terms are considered 223 small in comparison to the dc quantities (obtained equilibrium 224 values), i.e.,

Third, by substituting (22)-(26) in (8) and (14)-(16), and tak- 226 ing into account that the products of two ac terms are negligible, 227 the small-signal model is derived. It can be written in matrix 228 form as follows:

$$
\begin{array}{r}
{\left[\begin{array}{cccc}
s L_{i} & M & 0 & 0 \\
-M & s C_{\mathrm{eq}} & n_{s} / n_{p} & 0 \\
0 & -n_{s} / n_{p} & s L_{o} & 1 \\
0 & 0 & -1 & s C_{o}+(1 / R)
\end{array}\right]\left[\begin{array}{c}
\hat{i}_{i}(s) \\
\hat{v}_{c}(s) \\
\hat{i}_{o}(s) \\
\hat{v}_{o}(s)
\end{array}\right]} \\
=\left[\begin{array}{c}
-V_{c} \\
I_{i} \\
0 \\
0
\end{array}\right] \cdot \hat{m}(s)
\end{array}
$$

where $s$ is the Laplace operator. Note that all the transfer func- 230 tions that characterize the behavior of the converter in small 231 signal can be derived from (32).

The obtained small-signal model constitutes the second con- 233 tribution of this paper. This model is then utilized for control 234 design as explained in Section IV.

\section{Proposed Control Scheme}

This section introduces a control scheme for the parallel- 237 resonant converter with two possible configurations for the ex- 238 ternal voltage loop. The internal current loop and the FM are 239 also presented in detail.

\section{A. Voltage and Current Control Loops}

Fig. 4 shows the diagram of the proposed control scheme. It 242 is based on two control loops and an FM. The internal control 243 loop makes the system controllable and limits the input cur- 244 rent. To this end, it processes the input current error using a 245 


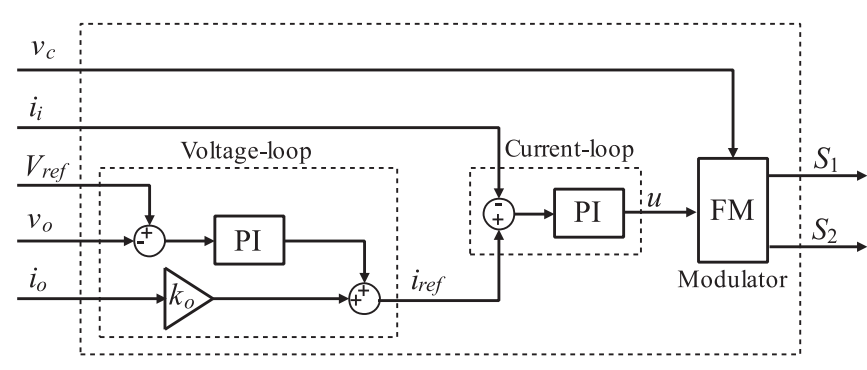

Fig. 4. Diagram of the two proposed control schemes. Basic configuration $\left(i_{o}\right.$ is not measured in this case and $\left.k_{o}=0\right)$ and enhanced configuration $\left(i_{o}\right.$ is measured in this case and $\left.k_{o}=V_{\text {ref }} / V_{i}\right)$.

proportional-integral (PI) regulator and provides the signal $u$ to the input of the modulator.

The external voltage loop is responsible to regulate the output voltage. It has two control terms: a feedback term that tries to eliminate the output voltage error using a PI regulator and a feedforward term of the output current. The feedback term ensures that the output voltage matches the reference voltage in steady state, thus compensating the effects of unmodeled elements such as parasitic resistors and transformer leakage inductances. In the case of load-step changes, the feed-forward term helps the modulator to rapidly find an appropriate switching frequency to ensure a fixed-output voltage, yielding in a fast transient response.

The proposed controller is called here basic configuration when $k_{o}=0$ and enhanced configuration when $k_{o}=I_{i} / I_{0}$. In the enhanced controller, the steady-state currents in the feedforward gain $k_{o}$ rely on the load condition. However, from (18) and (20) and assuming $V_{o}=V_{\text {ref }}$, the feed-forward gain is independent of the load condition and can be written as

$$
k_{o}=\frac{V_{\mathrm{ref}}}{V_{i}} .
$$

The enhanced controller is introduced in order to improve the transient response, i.e, to get a negligible output voltage deviation and lower settling time. This is considered as the benefit of this control configuration. However, an additional measurement $i_{o}$ is required in this case, slightly increasing the cost of the system.

\section{B. Frequency Modulator}

This section proposes an FM for the CSPRC. The modulator is derived from the phase modulator presented in [37] for voltage-source resonant converters. The differences between both modulators are also highlighted below.

Fig. 5(a) shows the proposed FM. It is based on the generation of a saw-tooth waveform synchronized by the zero crossing detection of the resonant capacitor voltage. This waveform is then compared with the output signal of the controller $u$ in order to generate the gate signals $\left(S_{1}\right.$ and $\left.S_{2}\right)$ by using an RS flip-flop. Fig. 5(b) shows the main waveforms of the modulator. Note that the switching period depends on the load conditions, as predicted by (21). It is worth mentioning that the ramp amplitude is always one in this modulator in order to modify the

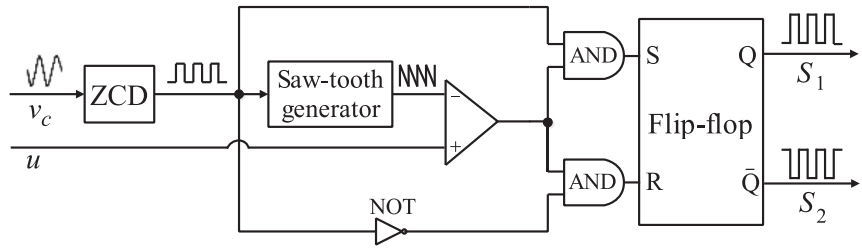

(a)

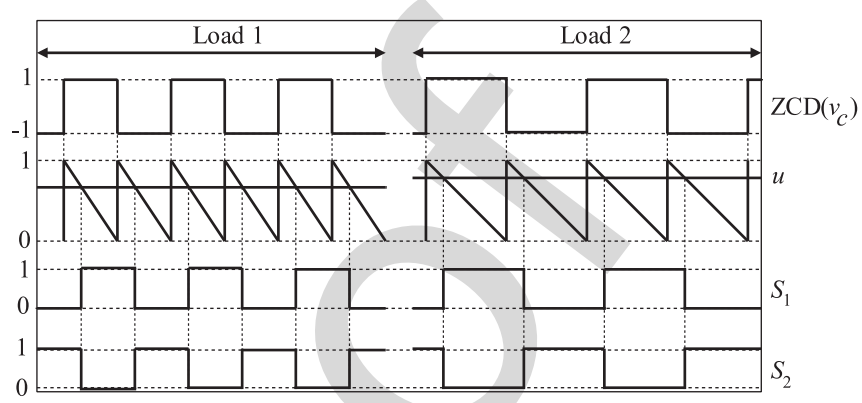

(b)

Fig. 5. Proposed FM including a variable slope, fixed amplitude sawtooth generator: (a) diagram and (b) main waveforms for two different load conditions.

switching period as a function of the load condition. The sawtooth generator produces this distinctive feature by means of a closed-loop control using a PI regulator; see details in [37]. The most promising feature of both modulators is the high robustness to resonant parameter variations. This feature is attributed to the sensing of the resonant tank state, through the measure of a resonant state variable. Thus, changes on resonant components due to temperature, tolerance, age, etc., are perfectly absorbed by the modulator. The main differences between the two modulators are as follows.

1) The resonant capacitor voltage instead of the inductor current is used to provide ZVS conditions.

2) The slope of the ramp signal is reversed to operate below resonance (the voltage-source resonant converter operates above resonance).

3) Only one input signal $u$ is required to regulate the output voltage (the phase modulator needs two signals).

The proposed control scheme is the third contribution of this paper. The novelties of this configuration are: first, the feedforward term included in the conventional two loop control in order to accelerate the transient response during load step changes; and second, the adaptive modulator used to synchronize the control action with the zero crossing of the resonant capacitor voltage, thus providing ZVS condition. In addition, the modulator provides a robust operation against internal and external disturbances (such as variations in resonant tank parameters and input voltage, respectively).

\section{Control DEsign}

This section presents the design procedure to obtain the gains of the two PI controllers used in the proposed control scheme. A numerical example is also included to illustrate the procedure in detail. This design procedure constitutes the fourth contribution 


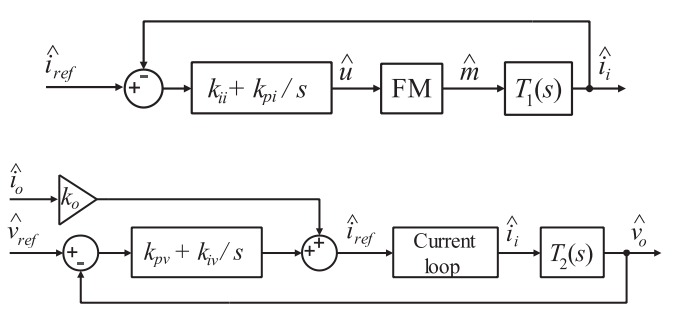

Fig. 6. Small-signal diagram of the (a) internal control loop and (b) external control loop.

of this paper. A numerical example is also included to illustrate the procedure in detail.

\section{A. Design Procedure}

The control design proceeds as follows.

1) The closed-loop transfer functions of the system are first obtained by using the derived small-signal model.

2) The frequency-domain specifications of the closed-loop system are fixed in terms of desired control BW and phase margin (PM).

3) The gain values of the PI controllers satisfying the specifications are selected.

To this end, Bode diagrams of different set of gain values are examined until the specifications are met.

\section{B. Closed-Loop Small-Signal Models}

Fig. 6 shows the small-signal diagram of the internal and external control loops. Note that the two PI controllers are included in the figure. The other transfer functions involved in the diagram are derived below.

The control to input-current $T_{1}(s)$ and input-current to outputvoltage $T_{2}(s)$ transfer functions are obtained from the smallsignal model expressed in (24). These transfer functions are

$$
\begin{aligned}
& T_{1}(s)=\frac{\hat{i}_{i}(s)}{\hat{m}(s)}=\frac{A_{1} s^{3}+A_{2} s^{2}+A_{3} s+A_{4}}{B_{1} s^{4}+B_{2} s^{3}+B_{3} s^{2}+B_{4} s+B_{5}} \\
& T_{2}(s)=\frac{\hat{v}_{o}(s)}{\hat{i}_{i}(s)}=\frac{C_{1} s+C_{2}}{B_{1} s^{4}+B_{2} s^{3}+B_{3} s^{2}+B_{4} s+B_{5}} .
\end{aligned}
$$

The coefficients of these transfer functions can be found in the Appendix.

The transfer function of the proposed modulator is deduced according to the following points and assumptions.

1) It is well known that the small-signal model of a modulator involving a ramp signal coincides with the inverse of the amplitude of this signal (i.e., $1 / V_{\text {ramp }}$ ) [36].

2) In the proposed modulator, a closed-loop control is used in the saw-tooth generator to fix the amplitude of the ramp signal to one $\left(V_{\text {ramp }}=1\right)$.

3) This control loop is fast enough compared to the BW of the internal and external control loops.

Thus, the transfer function of the modulator can be expressed as

$$
\frac{\hat{m}}{\hat{u}}=\frac{1}{V_{\text {ramp }}}=1 .
$$

TABLE II

FREQUENCY-DOMAIN SPECIFICATIONS

\begin{tabular}{lcc}
\hline \hline Control loops & BW $(\mathrm{kHz})$ & $\mathrm{PM}\left({ }^{\mathrm{o}}\right)$ \\
\hline Current loop & 7.467 & 60 \\
Voltage loop & 0.593 & 60 \\
\hline \hline
\end{tabular}

TABLE III

Values of the Control Gains and Parameters

\begin{tabular}{llc}
\hline \hline Symbol & \multicolumn{1}{c}{ Quantity } & Value \\
\hline$k_{p i}$ & Current-loop proportional gain & $0.4 \mathrm{~A}^{-1}$ \\
$k_{i i}$ & Current-loop integral gain & $30 \mathrm{~Hz} / \mathrm{A}$ \\
$k_{p v}$ & Voltage-loop proportional gain & $0.01 \Omega^{-1}$ \\
$k_{i v}$ & Voltage-loop integral gain & $120 \mathrm{~Hz} / \Omega$ \\
$k_{o}$ & Feed-forward gain (basic control) & 0 \\
$k_{o}$ & Feed-forward gain (enhanced control) & 2.9 \\
$V_{\text {ref }}$ & Reference output voltage & $35 \mathrm{~V}$ \\
\hline \hline
\end{tabular}

The design of the PI controllers is based on making the dy- 352 namic characteristics meet the control design specifications. 353

Table II lists these specifications for the internal and external 354 control loops. In the internal current loop, the control BW is 355 1.1 decades below the minimum switching frequency to get a 356 fast current transient response. In the external voltage loop, the 357 control BW is 1.1 decades below the control BW specification of 358 the current loop in order to avoid undesired interactions between 359 these control loops. The PMs are high enough to prevent the 360 converter from going to the instability region.

The dynamic characteristics of the CSPRC can be extracted 362 from the current and voltage loop gains. From Fig. 6, these 363 transfer functions can be written as

$$
\begin{aligned}
T_{i}(s) & =\left[k_{p i}+\frac{k_{i i}}{s}\right] T_{1}(s) \\
T_{v}(s) & =\left[k_{p v}+\frac{k_{i v}}{s}-\frac{k_{o}}{R}\right] T_{2}(s) .
\end{aligned}
$$

Note that the loop gains depend directly on the gains of the 365 two PI controllers, as usual. In the voltage loop gain, a perfect 366 tracking of the reference current is assumed, i.e., $\hat{i}_{i}(s) / \hat{i}_{\text {ref }}(s)=367$ 1. This is actually a good approximation due to the reduced 368 control BW of the voltage loop. In addition, the feed-forward 369 term $k_{o}$ appears in the voltage loop gain, so that the dynamic 370 characteristics will be analyzed for: the current loop, the basic 371 voltage loop $\left(k_{o}=0\right)$, and the enhanced voltage loop $\left(k_{o}=372\right.$ $V_{\text {ref }} / V_{i}$ ). Hence, the impact of $k_{o}$ on the transient response will 373 be also analyzed considering the closed-loop transfer function 374 shown in (38), derived from the small-signal model.

\section{Design of the Internal and External Control Loops}

The values of the PI gains are obtained according to the 377 design specifications. Several Bode diagrams are represented 378 with different PI gains until the specifications are met. Once 379 this process is finished, the final values of the PI gains are 380 captured and listed in Table III. The values of the feed-forward 381 


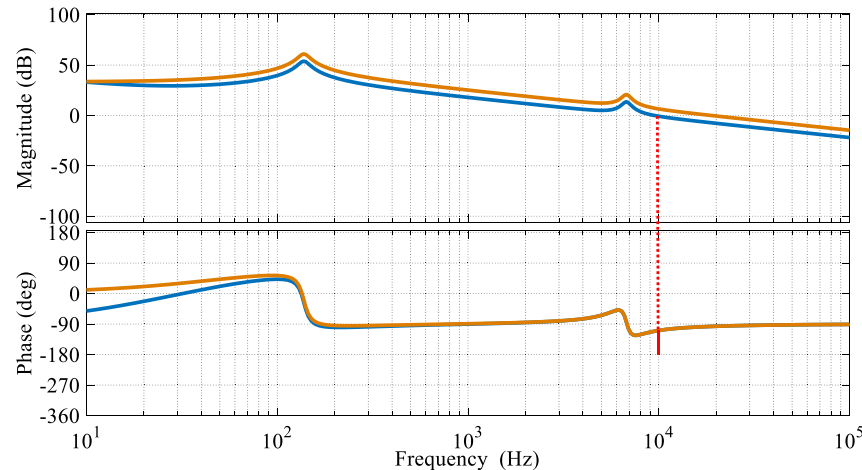

(a)

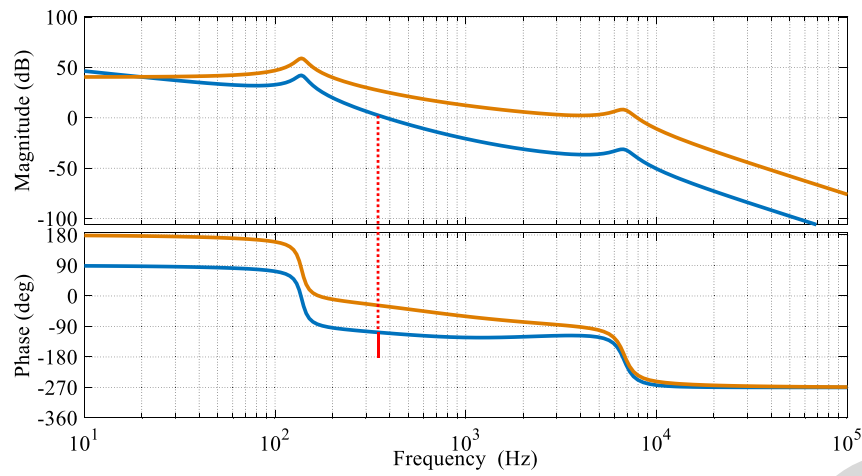

(b)

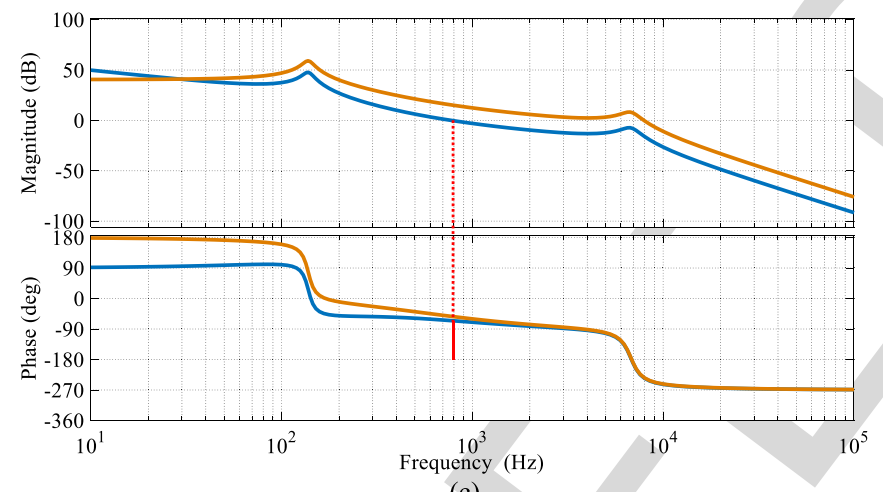

(c)

Fig. 7. Bode diagrams of (a) current loop gain, (b) voltage loop gain for the basic control $\left(k_{o}=0\right)$, and (c) voltage loop gain for the enhanced control $\left(k_{o}=V_{\text {ref }} / V_{i}\right)$ for FL condition (blue: compensated and orange: uncompensated). gains for the basic and the enhanced control configurations are also included in the table. Fig. 7 shows the Bode diagram of the loop gains for both compensated and uncompensated system at FL condition. Note that the compensated system reduces the control BW to reach the design specifications, as depicted in Fig. 7.

For the current loop, the control BW is $9.43 \mathrm{kHz}$ and the PM is $67.1^{\circ}$, meeting satisfactorily the design specifications. In the basic voltage loop, although the PM is good enough $\left(70.4^{\circ}\right)$, the control BW $(0.35 \mathrm{kHz})$ is lower than the specification. Thanks to the feed-forward term, the enhanced voltage loop shows superior performance by increasing both the control BW $(0.81 \mathrm{kHz})$ and the PM $\left(116.4^{\circ}\right)$. The design specifications are clearly meet by the enhanced control configuration.
TABLE IV

DYNAMIC CHARACTERISTICS FOR DIFFERENT LOAD CONDITIONS

\begin{tabular}{|c|c|c|c|c|c|}
\hline \multirow[t]{2}{*}{ Control scheme } & \multirow[t]{2}{*}{ Load condition } & \multicolumn{2}{|c|}{ Current loop } & \multicolumn{2}{|c|}{ Voltage loop } \\
\hline & & BW (kHz) & $\operatorname{PM}\left({ }^{\circ}\right)$ & BW (kHz) & $\operatorname{PM}\left({ }^{\circ}\right)$ \\
\hline Basic & FL & 9.43 & 67.1 & 0.35 & 70.4 \\
\hline$\left(k_{o}=0\right)$ & $10 \%$ of FL & 8.52 & 85.2 & 0.23 & 98.2 \\
\hline Enhanced & FL & 9.43 & 67.1 & 0.81 & 116.4 \\
\hline$\left(k_{o}=V_{\text {ref }} / V_{i}\right)$ & $10 \%$ of FL & 8.52 & 85.2 & 0.67 & 153.3 \\
\hline
\end{tabular}

TABLE V

PROTOTYPE COMPONENTS

\begin{tabular}{lc}
\hline \hline Component & Model \\
\hline Diodes & 20ETF08S \\
MOSFETs & IRFR4620 \\
MOSFET driver & MCP14E10 \\
Resonant capacitor & MKT type \\
Op-amps & MCP6022 \\
\hline \hline
\end{tabular}

Table IV shows the dynamic characteristics for different load conditions. Note that the control BW improves as the load increases for both control loops. Conversely, the PM deteriorates as the load increases. Anyway, the design specifications are meet for the current loop and the enhanced voltage loop. In addition, the enhanced voltage loop improves the dynamic characteristics of the basic voltage loop for all load conditions.

\section{EXPERIMENTAL RESULTS}

This section validates the proposed control scheme with selected experimental results from a laboratory prototype.

\section{A. Laboratory Prototype}

A 60-W laboratory prototype was built including a dcdc class-D CSPRC with a SPIC33FJ16GS504-I/PT microcontroller as digital control platform. The input and output currents were sensed with current transducers (LTP-15NP). Simple ana$\log$ circuits including differential amplifiers are used to sense the resonant capacitor and output voltages. Other prototype components are listed in Table V. Fig. 8 shows the top and bottom views of the laboratory prototype.

\section{B. Evaluation of Static Characteristics}

In this section, the steady-state operation of the CSPRC is evaluated.

Fig. 9 shows the steady-state voltage across the right leg of the class-D inverter shown in Fig. 1 (including the voltages in MOSFET S2 and blocking diode D2) and its associated current for both FL and $10 \%$ of FL. Note that the waveform of the switch voltage is similar in both load conditions. The only notable difference is a change in the switching frequency. However, in the switch current waveform, the change in both switching frequency and in amplitude is observed. These features were theoretically predicted by (18)-(21), as discussed in Section V-C. 


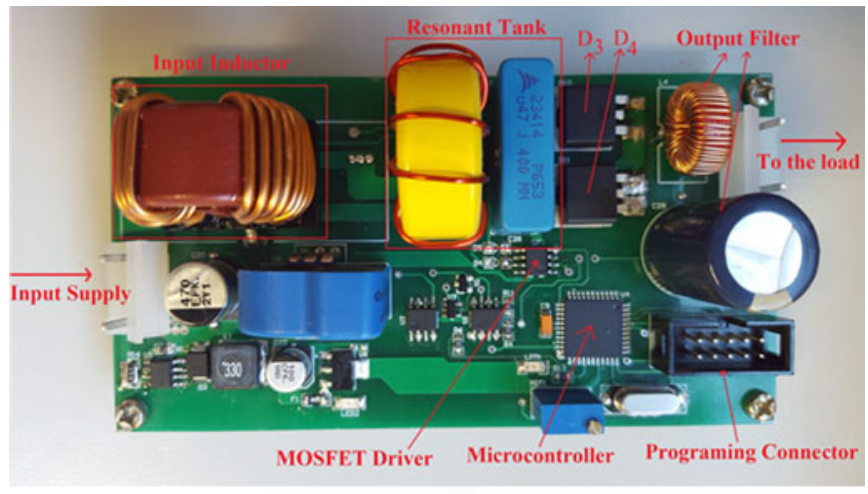

(a)

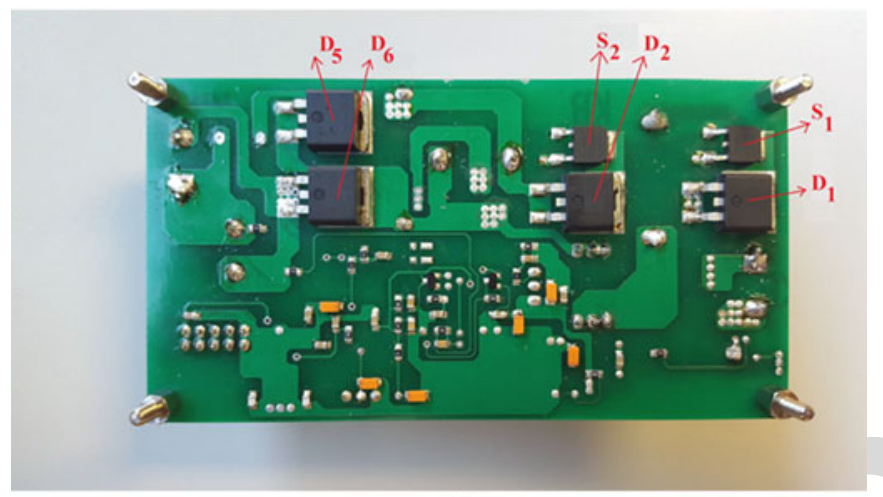

(b)

Fig. 8. Experimental dc-dc CSPRC prototype: (a) top view and (b) bottom view.

Fig. 9 also reveals the ZVS operation of the CSPRC. When the switch is OFF (interval with zero switch current), the switch voltage tracks the resonant capacitor voltage by changing sinusoidally from positive to negative values. In the interval with negative values, the diode D2 is naturally in OFF state and then MOSFET S2 can be driven to ON state. In this case, although S2 is ON, no current flows through the switch due to the blocking diode D2. Thus, the MOSFET S2 is in ON state with zero voltage across before switch current increases during the switch transition from OFF to ON. This mechanism is known as ZVS operation and is characterized by negligible switching losses.

Fig. 10 shows the system efficiency as a function of the output power. The highest efficiency (95\%) is obtained at $55 \mathrm{~W}(90 \%$ of full power). As usual, the efficiency deteriorates as output power reduces, being $91.1 \%$ the lowest efficiency measured at $15 \mathrm{~W}$ ( $25 \%$ of full power).

\section{Evaluation of Dynamic Characteristics}

Fig. 11(a) shows the transient response of the output voltage during load step changes using the basic control configuration. Note that the load changes produce significant voltage deviations and large settling times. Fig. 11(b) depicts the transient response of the resonant capacitor voltage, showing a similar dynamic. Note that the steady-state amplitude of the resonant capacitor voltage is constant, independent of the load. This fact was predicted theoretically by (18), (20), and (21). The

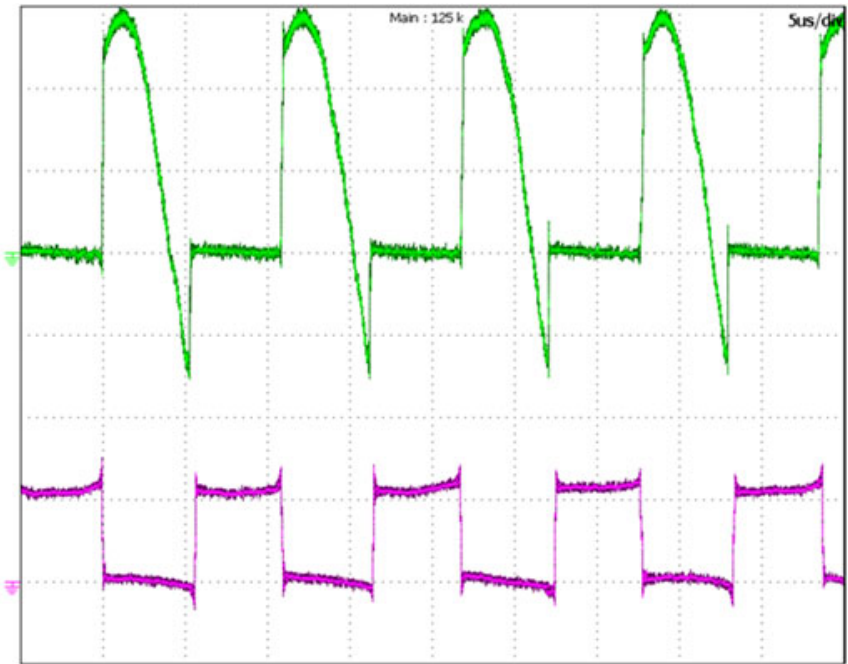

(a)

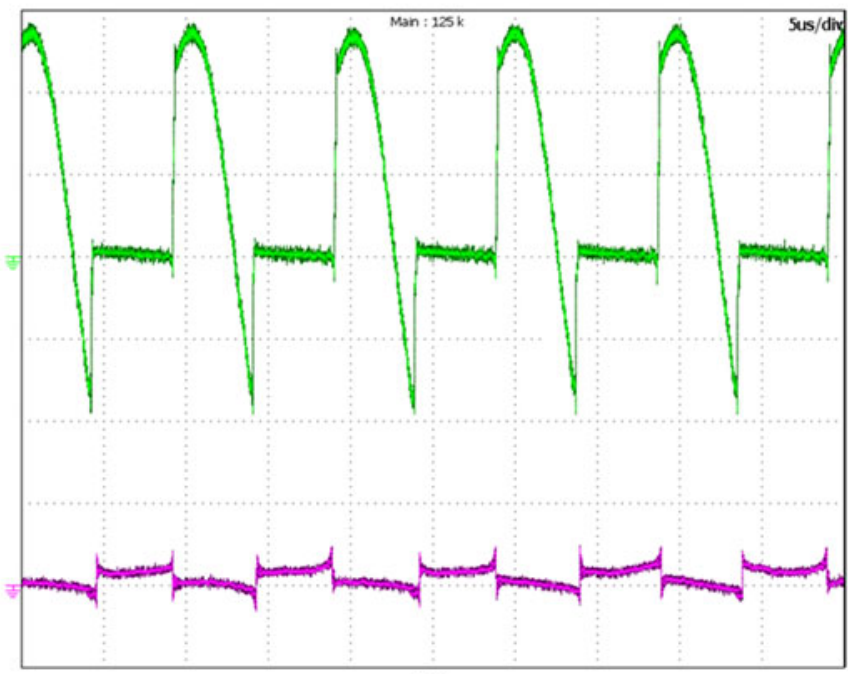

(b)

Fig. 9. Steady-state switch voltage (green, $20 \mathrm{~V} / \mathrm{div}, 5 \mu \mathrm{s} / \mathrm{div}$ ) and current (pink, $5 \mathrm{~A} /$ div) for: (a) FL and (b) $10 \%$ of FL.

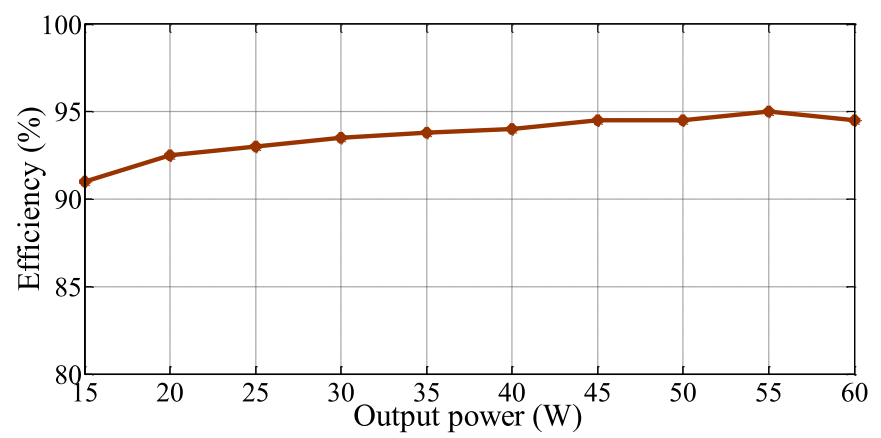

Fig. 10. System efficiency as a function of output power.

control scheme modifies the switching frequency when the load 452 changes to maintain $M$ constant in steady state; see (21). By this 453 mechanism, the output voltage and the amplitude of the reso- 454 nant capacitor voltage are constants in steady state, as observed 455 in (18) and (20). Conversely, the input and output currents rely 456 


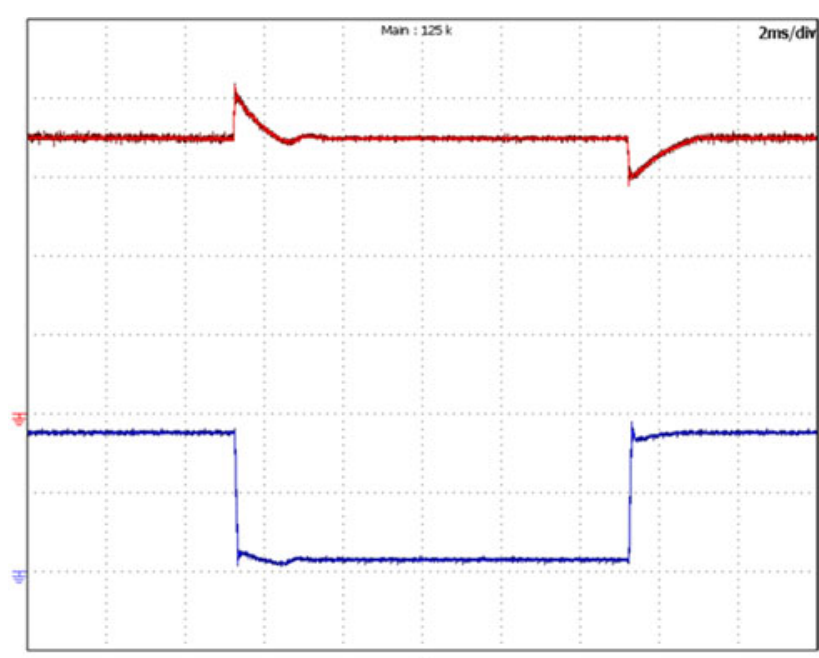

(a)

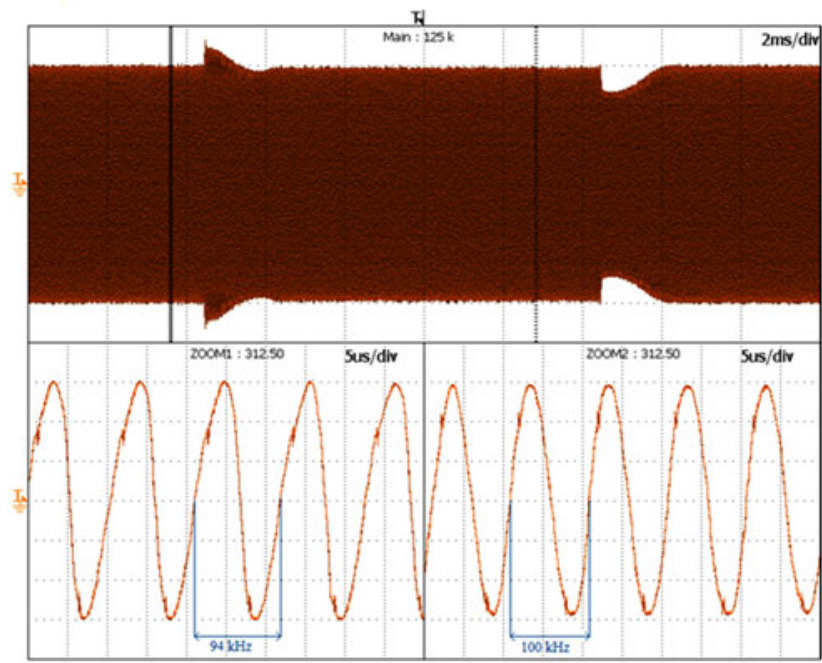

(b)

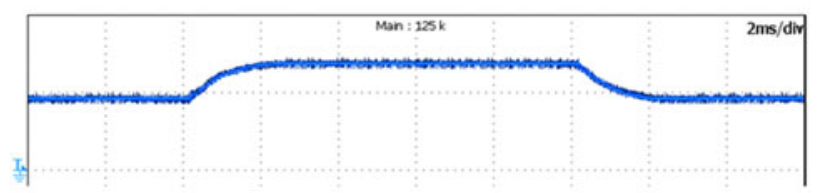

(c)

Fig. 11. Load transient response of the basic control configuration $\left(k_{o}=0\right)$ : (a) output voltage (red, $10 \mathrm{~V} / \mathrm{div}, 2 \mathrm{~ms} / \mathrm{div}$ ) and current (blue, $1 \mathrm{~A} /$ div), (b) resonant capacitor voltage (20 V/div, $2 \mathrm{~ms} / \mathrm{div}), v_{c}$ zoom (5 $\mu \mathrm{s} / \mathrm{div})$, and (c) signal $u(2 \mathrm{~V} / \mathrm{div}, 2 \mathrm{~ms} / \mathrm{div})$. on the load condition, as predicted by (17) and (19). The areas marked in Fig. 11(b) have been zoomed-in and shown in the lower side of this figure. As it can be seen, the switching frequency increases from 94 to $100 \mathrm{kHz}$ to regulate the output voltage when the load changes from FL to $10 \%$ of FL. These experimental measures are well matched with the theoretical results shown in Fig. 2. It is interesting to observe that the quality of the resonant waveforms improves when the switching frequency approaches the resonant frequency. Furthermore, Fig. 11(c) shows the transient response of the input signal of the modulator $(u)$. Note that the basic control has slow dynamics with a settling time around $2 \mathrm{~ms}$.

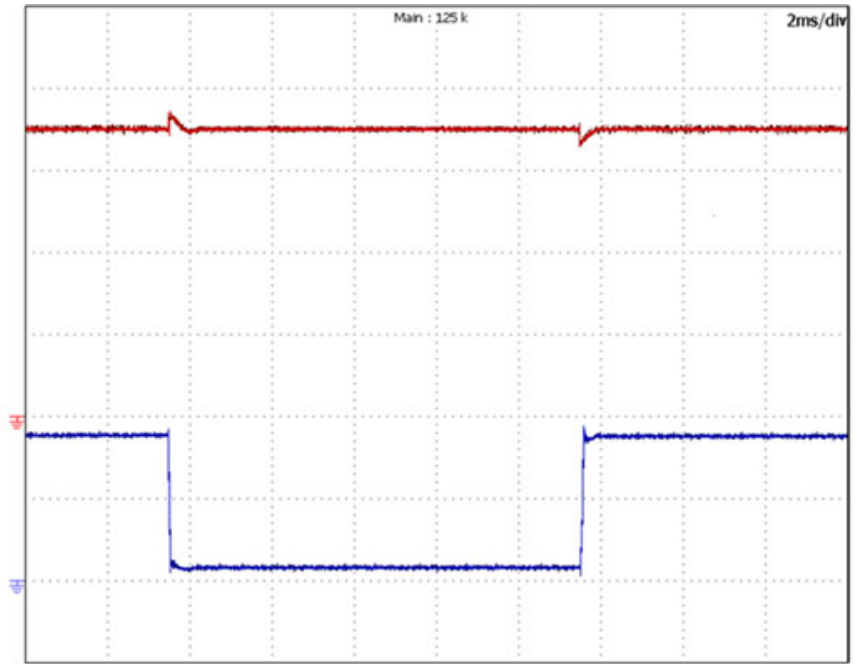

(a)

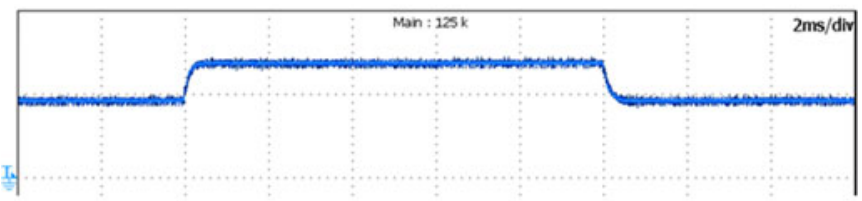

(b)

Fig. 12. Load transient response of the enhanced control configuration $\left(k_{o}=V_{\mathrm{ref}} / V_{i}\right):(\mathrm{a})$ output voltage (red, $\left.10 \mathrm{~V} / \mathrm{div}, 2 \mathrm{~ms} / \mathrm{div}\right)$ and current (blue, $1 \mathrm{~A} / \mathrm{div})$, and (b) signal $u(2 \mathrm{~V} / \mathrm{div}, 2 \mathrm{~ms} / \mathrm{div})$.

Fig. 12(a) shows the transient response of the output voltage 469 during load changes using the enhanced control. As predicted 470 by Fig. 7(c) and Table IV, the transient response is drastically 471 improved. In fact, the voltage overshoots and setting times are 472 clearly reduced from 5 to $1 \mathrm{~V}$ and from 1.8 to $0.4 \mathrm{~ms}$, respec- 473 tively. These enhancements are the consequence of the transient 474 response improvement in the input signal of the modulator $(u), \quad 475$ as depicted in Fig. 12(b). It means that in the case of load-step 476 changes, the feed-forward term helps the modulator to rapidly 477 find an appropriate switching frequency to ensure a fixed-output 478 voltage.

The load transient response is also evaluated for different values of the input voltage. Fig. 13 shows the results for $V_{i}=$ $10 \mathrm{~V}$ and Fig. 14 for $V_{i}=14 \mathrm{~V}$. Note that the voltage deviations during load changes reduce as the input voltage increases (i.e., when the gain of the converter reduces).

In any case, the most important issue is that the dynamic behavior of the enhanced control is still superior than the performance of the basic control for any value of the input voltage; compare Figs. 11-14. In particular, the transient response is faster with lower voltage deviations and settling times (benefit of the enhanced control), as expected from the theoretical analysis.

However, the drawback associated to the enhanced control is the additional measurement $\left(i_{o}\right)$ required to implement the feed-forward term, increasing the overall cost of the system. Therefore, regarding the desired performance and cost, one of the two proposed control configurations should be applied to the converter.
69 0 41

75

76




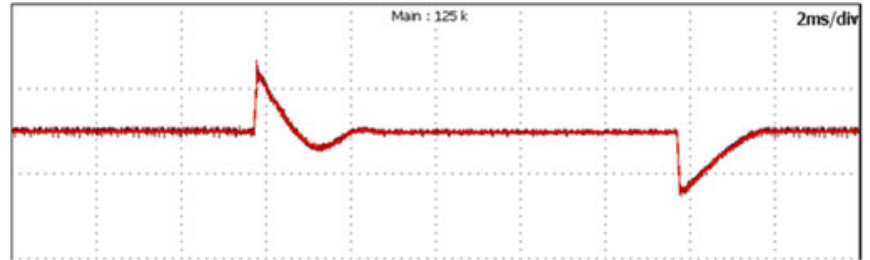

(a)

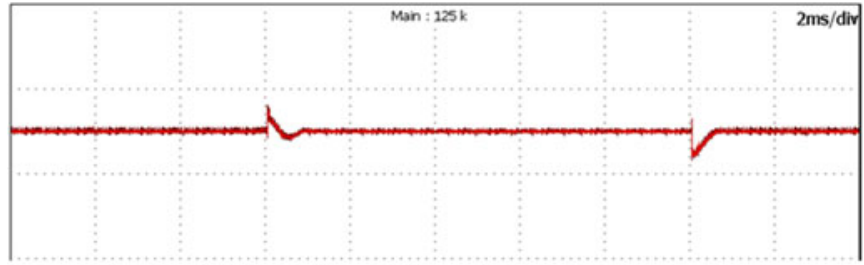

(b)

Fig. 13. Load transient response for $V_{i}=10 \mathrm{~V}$ and $V_{\text {ref }}=35 \mathrm{~V}$ (a) Basic control configuration $\left(k_{o}=0\right)$. (b) Enhanced control configuration $\left(k_{o}=V_{\text {ref }} / V_{i}\right)$. $10 \mathrm{~V} /$ div, $2 \mathrm{~ms} /$ div.

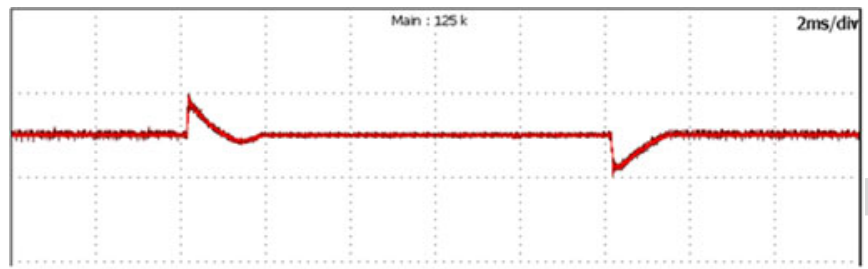

(a)

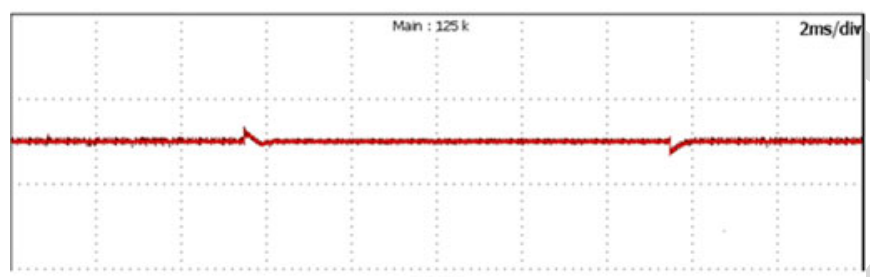

(b)

Fig. 14. Load transient response for $V_{i}=14 \mathrm{~V}$ and $V_{\text {ref }}=35 \mathrm{~V}$. (a) Basic control configuration $\left(k_{o}=0\right)$. (b) Enhanced control configuration $\left(k_{o}=V_{\text {ref }} / V_{i}\right)$. $10 \mathrm{~V} /$ div, $2 \mathrm{~ms} /$ div.

\section{CONCLUSION}

modifying the logic circuit of the modulator. The proposed control configurations were promising closed-loop control systems to be employed in switching power supplies. The extension to other applications was left for future research work.

\section{APPENDIX}

This Appendix shows the coefficients of the transfer functions expressed in (34) and (35)

$$
\begin{aligned}
& A_{1}=V_{c}+I_{i} M R \\
& A_{2}=C L_{o} V_{c}+C_{o} I_{i} L_{o} M R \\
& A_{3}=I_{i} L_{o} M+C R V_{c}+C_{o} R V_{c} \\
& A_{4}=V_{c}+I_{i} M R \\
& B_{1}=C C_{o} L_{i} L_{o} R \\
& B_{2}=C L_{i} L_{o} \\
& B_{3}=C L_{i} R+C_{o} L_{i} R+C_{o} L_{o} M^{2} R \\
& B_{4}=L_{i}+L_{o} M^{2} \\
& B_{5}=M^{2} R \\
& C_{1}=I_{i} M R L_{i} \\
& C_{2}=-R M V_{c} .
\end{aligned}
$$

\section{REFERENCES}

[1] H. Sarnago, O. Lucia, A. Mediano, and J. M. Burdio, "Modulation scheme 524 for improved operation of an RB-IGBT-based resonant inverter applied to domestic induction heating," IEEE Trans. Ind. Electron., vol. 60, no. 5, pp. 2066-2073, May 2013.

[2] W. Li, H. Zhao, S. Li, J. Deng, T. Kan, and C. C. Mi, "Integrated LCC 528 compensation topology for wireless charger in electric and plug-in electric 529 vehicles," IEEE Trans. Ind. Electron., vol. 62, no. 7, pp. 4215-4225, 530 Jul. 2015.

[3] Y. Wang, Y. Guan, K. Ren, W. Wang, and D. Xu, "A single-stage LED 532 driver based on BCM boost circuit and LLC converter for street light- 533 ing system," IEEE Trans. Ind. Electron., vol. 62, no. 9, pp. 5446-5457, 534 Sep. 2015. ers for driving high-voltage actuators in mobile microrobots," IEEE Trans. 537 Power Electron., vol. 31, no. 1, pp. 340-352, Jan. 2016.

[5] O. Lucia, J. M. Burdio, I. Millan, J. Acero, and D. Puyal, "Load adap- 539 tive control algorithm of half-bridge series resonant inverter for do- 540 mestic induction heating," IEEE Trans. Ind. Electron., vol. 56, no. 8, 541 pp. 3106-3116, Aug. 2009.

[6] K. Yan, Q. Chen, J. Hou, X. Ren, and X. Ruan, "Self-oscillating contactless 543 resonant converter with phase detection contactless current transformer," 544 IEEE Trans. Power Electron., vol. 29, no. 8, pp. 4438-4449, Aug. 2014. 545

[7] A. Moradewicz and P. Kazmierkowski, "Novel FPGA based control of se- 546 ries resonant converter for contactless power supply," in Proc. EUROCON, 547 2007, pp. 1328-1335. mode control for a multiple-user inductive power transfer system without 550 need for communication," IEEE Trans. Ind. Electron., vol. 60, no. 1, 551 pp. 271-279, Jan. 2013.

[9] P. Xuewei and A. K. Rathore, "Novel bidirectional snubberless naturally 553 commutated soft-switching current-fed full-bridge isolated DC/DC con- 554 verter for fuel cell vehicles," IEEE Trans. Ind. Electron., vol. 61, no. 5, 555 pp. 2307-2315, May 2014.

[10] S. S. Lee, S. Iqbal, and M. Kamarol, "Control of ZCS-SR inverter-fed 557 voltage multiplier-based high-voltage DC-DC converter by digitally tun- 558 ing tank capacitance and slightly varying pulse frequency," IEEE Trans. 559 Power Electron., vol. 27, no. 3, pp. 1076-1083, Mar. 2012.

[11] K. R. Sree and A. K. Rathore, "Impulse commutated zero-current switch- 561 ing current-fed push-pull converter: Analysis, design, and experimental 562 results," IEEE Trans. Ind. Electron., vol. 62, no. 1, pp. 363-370, Jan. 2015. 563 
[12] S. Iqbal, G. K. Singh, and R. Besar, "A dual-mode input voltage modulation control scheme for voltage multiplier based X-ray power supply," IEEE Trans. Power Electron., vol. 23, no. 2, pp. 1003-1008, Mar. 2008.

[13] M. A. Halim, M. N. Hidayat, and M. N. Seroji, "Implementation and analysis of a half-bridge series-parallel LLC loaded resonant DC-DC converter for low power applications," in Proc. IEEE Power Electron. Drive Syst., 2013, pp. 634-638.

[14] D. Reusch and J. Strydom, "Evaluation of gallium nitride transistors in high frequency resonant and soft-switching DC-DC converters," IEEE Trans. Power Electron., vol. 30, no. 9, pp. 5151-5158, Sep. 2015.

[15] X. Zhang, T. C. Green, and A. Junyent-Ferré, "A new resonant modular multilevel step-down DC-DC converter with inherent-balancing," IEEE Trans. Power Electron., vol. 30, no. 1, pp. 78-88, Jan. 2015.

[16] J. T. Boys, G. A. Covic, and A. W. Green, "Stability and control of inductively coupled power transfer system," Proc. Inst. Elect. Eng.-Elect. Power Appl., vol. 147, no. 1, pp. 37-43, Jan. 2000.

[17] M. G. Kim and M. J. Youn, "An energy feedback control of series resonant converters," IEEE Trans. Power Electron., vol. 6, no. 4, pp. 338-345, Jul. 1991.

[18] D. J. Tschirhart and P. K. Jain, "A CLL resonant asymmetrical pulse width modulated converter with improved efficiency," IEEE Trans. Ind. Electron., vol. 55, no. 1, pp. 114-122, Jan. 2008.

[19] V. Esteve, "Improving the efficiency of IGBT series resonant inverters using pulse density modulation," IEEE Trans. Ind. Electron., vol. 58, no. 3, pp. 979-987, Mar. 2011

[20] L. A. Barragan, D. Navarro, J. Acero, I. Urriza, and J. M. Burdio, "FPGA implementation of a switching frequency modulation circuit for EMI reduction in resonant inverters for induction heating appliances," IEEE Trans. Ind. Electron., vol. 55, no. 1, pp. 11-20, Jan. 2008.

[21] J. M. Carrasco, E. Galván, G. E. Valderrama, R. Ortega, and A. Stankovic, "Analysis and experimentation of nonlinear adaptive controllers for the series resonant converter,' IEEE Trans. Power Electron., vol. 15, no. 3, pp. 536-544, May 2000.

[22] M. Castilla, L. García de Vicuña, M. López, O. López, and J. Matas, "On the design of sliding mode control schemes for quantum resonant converters," IEEE Trans. Power Electron., vol. 15, no. 6, pp. 960-973, Nov. 2000.

[23] I. H. Cho, Y. D. Kim, and G. W. Moon, "A half-bridge LLC resonant converter adopting boost PWM control scheme for hold-up state operation," IEEE Trans. Power Electron., vol. 29, no. 2, pp. 841-850, Feb. 2014.

[24] M. K. Kazimierczuk and D. Czarkowski, Resonant Power Converters. New York, NY, USA: Wiley, 1995.

[25] A. Momeneh, M. Castilla, F. Van Der Pijl, M. Moradi, and J. Torres, "New inductive contactless energy transfer system for residential distribution networks with multiple mobile loads," in Proc. Eur. Conf. Power Electron. Appl., Sep. 2015, pp. 1-10.

[26] A. P. Hu, G. A. Covic, and J. T. Boys, "Direct ZVS start-up of a current fed resonant inverter," IEEE Trans. Power Electron., vol. 21, no. 3, pp. 809-812, May 2006.

[27] A. Namadmalan and J. S. Moghani, "Self-oscillating switching technique for current source parallel resonant induction heating systems," J. Power Electron., vol. 12, no. 6, pp. 851-858, Nov. 2012.

[28] A. Namadmalan and J. S. Moghani, "Tunable self-oscillating switching technique for current source induction heating systems," IEEE Trans. Power Electron., vol. 61, no. 5, pp. 2556-2563, May 2014

[29] A. Namadmalan, "Bidirectional current fed resonant inverter for contactless energy transfer systems," IEEE Trans. Ind. Electron., vol. 62, no. 1, pp. 238-245, Jan. 2015

[30] H. Koizumi, "A delta-sigma modulated class-D current-source resonant boost converter," in Proc. Annu. meeting IEEE Ind. Electron. Soc., 2010, pp. 269-273.

[31] M. Castilla, L. García de Vicuña, M. Lopez, and J. Font, "A sliding mode controller for the current-source parallel-resonant converter with zero-voltage switching," in Proc. Annu. Meeting IEEE Ind. Electron. Soc., 1997, pp. 477-482.

[32] M. Castilla, L. García de Vicuña, M. Lopez, and V. Barcons, “An averaged large-signal modeling method for resonant converters," in Proc. Annu. Meeting IEEE Ind. Electron. Soc., 1997, pp. 447-452.

[33] M. Castilla, L. García de Vicuña, J. M. Guerrero, J. Matas, and J. Miret, "Sliding-mode control of quantum series-parallel resonant converters via input-output linearization," IEEE Trans. Ind. Electron., vol. 52, no. 2, pp. 566-575, Apr. 2005.

[34] J. L. Sosa, M. Castilla, J. Miret, L. García de Vicuña, and L. S. Moreno, "Sliding-mode input-output linearization controller for the DC/DC ZVS CLL-T resonant converter," IEEE Trans. Ind. Electron., vol. 59, no. 3, pp. 1554-1564, Mar. 2012.
[35] L. García de Vicuña, M. Castilla, J. Miret, J. Matas, and J. M. Guerrero, "Sliding-mode control for a single-phase AC/AC quantum resonan converter," IEEE Trans. Ind. Electron., vol. 56, no. 9, pp. 3496-3504, Sep. 2009

[36] R. W. Erikson and D. Maksimovic, Fundamentals of Power Electronics. New York, NY, USA: Kluwer, 2004.

[37] J. L. Sosa, M. Castilla, J. Miret, L. García de Vicuña, and J. Matas, "Modeling and performance analysis of the DC/DC series-parallel resonant converter operating with discrete self-sustained phase-shift modulation technique," IEEE Trans. Ind. Electron., vol. 56, no. 3, pp. 697-705, Mar. 2009

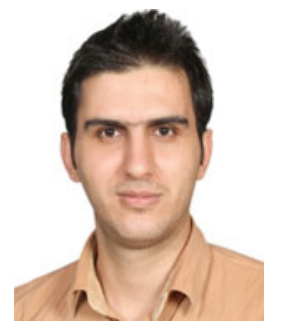

Mohammad Moradi Ghahderijani was born in Ghahderijan, Iran, in 1986. He received the M.S degree in electrical engineering from the University of Sistan and Baluchestan, Zahedan, Iran, in 2012. Since 2014, he has been working toward the Ph.D. degree in electronic engineering at the Technical University of Catalonia, Barcelona, Spain.

In 2013, he joined the Isfahan Regional Electric Company, Isfahan, Iran. His research in terests include power electronics, control, and renewable energy-based microgrids.

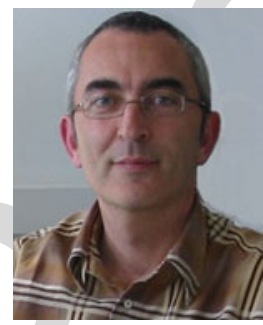

Miguel Castilla received the B.S., M.S., and Ph.D. degrees in telecommunication engineering from the Technical University of Catalonia, Barcelona, Spain, in 1988, 1995, and 1998, respectively.

Since 2002, he has been an Associate Professor with the Department of Electronic Engineering, Technical University of Catalonia, where he teaches courses on analog circuits and power electronics. His research interests include power electronics, nonlinear control, and renew-

able energy systems.

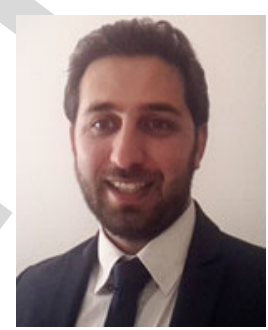

Arash Momeneh received the M.S. degree in electronic engineering from Razi University, Kermanshah, Iran, in 2010, and the Ph.D. degree in power electronic engineering from the Technical University of Catalonia, Barcelona, Spain, in 2016.

$\mathrm{He}$ is currently with the Applus IDIADA Company, Tarragona, Spain. His research interests include power electronics, electric vehicles, and renewable energy systems.

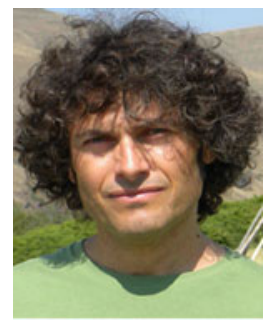

Jaume Tomas Miret (M'98) received the B.S degree in telecommunications, the M.S. degree in electronics, and the Ph.D. degree in electronics from the Technical University of Catalonia Barcelona, Spain, in 1992, 1999, and 2005, respectively.

From 1993 to 2011, he was an Assistant Professor with the Department of Electronic Engineering, Technical University of Catalonia. Since 2011, he has been an Associate Professor at the Technical University of Catalonia, where he teaches courses on digital design and circuit theory. His research interests include dc-to-ac converters, active power filters, and digital control.

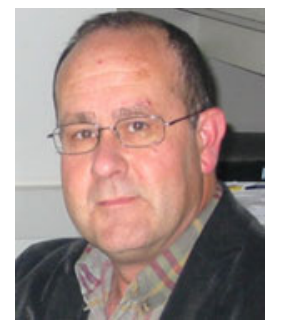

Luis Garcia de Vicuña received the M.S. and Ph.D. degrees in telecommunication engineering from the Technical University of Catalonia, Barcelona, Spain, in 1980 and 1990, respectively, and the Ph.D. degree in electrical engineering from Paul Sabatier University, Toulouse, France, in 1992.

From 1980 to 1982, he was an Engineer with a control applications company in Spain. He is currently a Full Professor in the Department of Electronic Engineering, Technical University of Catalonia, where he teaches courses on power electronics. His research interests include power electronics modeling, simulation and control, active power filtering, and high-power-factor ac/dc conversion.

641 642 643 644 645 646 647 648 649 650 651 


\section{Queries}

719 Q1. Author: Please provide the expansion of "RS" at its first occurrence in the text. 


\title{
Frequency-Modulation Control of a DC/DC Current-Source Parallel-Resonant Converter
}

\author{
Mohammad Moradi Ghahderijani, Miguel Castilla, Arash Momeneh, Jaume Tomas Miret, Member, IEEE, \\ and Luis Garcia de Vicuña
}

\begin{abstract}
This paper proposes a frequency-modulation control scheme for a dc/dc current-source parallel-resonant converter with two possible configurations. The basic configuration comprises an external voltage loop, an internal current loop, and a frequency modulator: the voltage loop is responsible for regulating the output voltage, the current loop makes the system controllable and limits the input current, and the modulator provides robustness against variations in resonant component values. The enhanced configuration introduces the output inductor current as a feed-forward term and clearly improves the transient response to fast load changes. The theoretical design of these control schemes is performed systematically by first deriving their small-signal models and second using Bode diagram analysis. The actual performance of the proposed control schemes is experimentally validated by testing on a laboratory prototype.
\end{abstract}

Index Terms-Control design, control systems, dc-dc power converters, frequency modulation, resonant converters.

\section{INTRODUCTION}

$\mathbf{S}$ INCE the emergence of the resonant technology, major $\checkmark$ research efforts have been conducted to apply the enhanced features of resonant converters to practical applications [1]-[8]. Induction heating [1], electric vehicle [2], lighting system [3], robotic industry [4], [5], and contactless energy-transfer system [6]-[8] are just a short list of examples. DC-DC conversion category is another industry example of great importance for these converters. Battery charging, electronic air purifiers, and switching power supplies are among these applications, ranging from low to high power [9]-[15]. A great interest has been taken in these converters due to their generated high frequency sinusoidal waveforms, reducing the electromagnetic interference and switching losses [16]. The control strategy has

Manuscript received September 2, 2016; revised December 5, 2016; accepted February 16, 2017. This work was supported in part by ELAC2014/ESE0034 from the European Union and its linked Spanish National Project PCIN-2015-001, in part by the Ministry of Economy and Competitiveness of Spain, and in part by the European Regional Development Fund (FEDER) under Project ENE2015-64087-C2-1-R.

The authors are with the Department of Electronic Engineering, Technical University of Catalonia, 08800 Barcelona, Spain (e-mail: mohammad.moradi.ghahderijani@upc.edu; miquel.castilla@upc.edu; arash.momenh@yahoo.com; jmiret@eel.upc.edu; vicuna@eel.upc. edu).

Color versions of one or more of the figures in this paper are available online at http://ieeexplore.ieee.org.

Digital Object Identifier 10.1109/TIE.2017.2677321 been one of the challenging research keys in this field. For voltage-source series-resonant converters, many control strategies have been analyzed and investigated [17]-[23], turning this into a mature technology nowadays. However, compared to the series-resonant topologies, parallel-resonant converters absorb a continuous smooth current from the input source, offering low current stress to switches [24]. Likewise, the reactive power circulates inside the parallel resonant tank and only the active power is supplied through the switches. This feature provides the capability of generating high current and voltage levels by using low VA-rated switches, reducing conduction losses. In addition, these converters provide more facilities such as short-circuited protection and paralleling capabilities. For the reasons outlined above, the research on the current-source parallel-resonant converters (CSPRC) has recently attracted more interest [25]-[31]. In particular, in [25], a current source topology has been proposed to supply a multireceiver inductive contactless energy transfer system. In this topology, a buck converter has been utilized to obtain an input current source with constant amplitude, supplying the resonant inverter. In [26], a simple modulation technique has been proposed for this type of converter and then applied to an induction heating system [27]. This method is then further developed in [28]. In [29], the modulation technique has been applied to an inductive contactless energy transfer system. A delta-sigma modulator is also applied to a class-D CSPRC in [30]. In all these works, the current-source converters operate in open loop and thus they exhibit a high sensitivity to external disturbances and parameter variations. In [31], a closed-loop control scheme with amplitude modulation has been presented for a dc/dc CSPRC. A robust behavior against load changes was demonstrated in this study by simulation results; however, some drawbacks inherent to the amplitude modulation limit its practical use.

The aim of this paper is to introduce a control scheme for the $\mathrm{dc} / \mathrm{dc}$ class-D CSPRC intended for switching power supplies. The control scheme has two possible configurations. The basic configuration is responsible for both regulating the output voltage and providing zero voltage switching (ZVS) conditions. A cascaded control scheme is proposed to this end, including an external voltage loop and an internal current loop. ZVS conditions are guaranteed by driving the switches with a robust frequency modulation technique. In addition, an enhanced control configuration is presented in this paper in order to further improve the load transient response of the basic configuration. The design of the control schemes is based on two steps. First, 


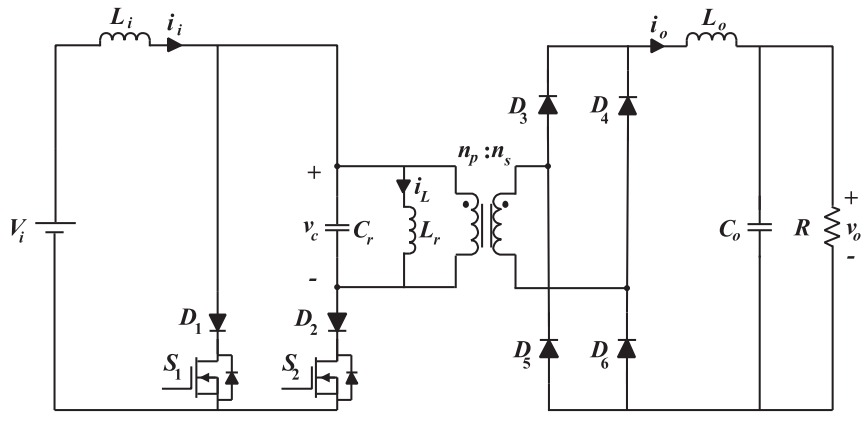

Fig. 1. Power circuit of the class-D CSPRC.

a dynamic model of the open-loop CSPRC is obtained. Afterward, the small-signal characteristics of the obtained averaged model are derived. Second, the dynamic model for the closedloop system is formulated and a systematic procedure to design the control gains is presented.

The theoretical contributions of this paper are: the large-signal model of the CSPRC operating with frequency modulation; 2) its small-signal model; 3 ) the control scheme, including the basic and enhanced control-loop configurations and the frequency modulator (FM); and 4) the systematic design procedure for deriving the control gains. As far as authors know, there are no previous studies exploring these four topics together or separately for the considered resonant topology.

This paper is structured as follows. Section II derives the large-signal model of the class-D CSPRC and its averaged smallsignal model. Section III introduces the basic and enhanced control configurations, including the FM. Section IV presents the design process of the proposed control scheme intended for $\mathrm{dc} / \mathrm{dc}$ applications. Section V verifies the theoretical contributions by selected experimental results in a laboratory prototype. Finally, Section VI gives the conclusions.

\section{Dynamic Modeling OF THE CLASS-D CSPRC}

Fig. 1 shows the power circuit of the dc/dc class-D CSPRC. The class-D resonant inverter includes an input inductor $\left(L_{i}\right)$, a second-order parallel-resonant tank $\left(L_{r}\right.$ and $\left.C_{r}\right)$ and a highfrequency transformer with winding turns ratio $n_{p}: n_{s}$. The resonant tank is loaded through a full-bridge diode rectifier and a second-order low-pass filter $\left(L_{o}\right.$ and $C_{o}$ ) to get a dc output voltage. The operation principle of this converter using frequency modulation was presented in detail in [24], and thus it is not repeated here.

The first contribution of this paper is the development of an adequate dynamic description of the class-D CSPRC converter for dc switching power supply applications. This model is essential for the control design process. Below is a step-by-step derivation of the dynamic model.

\section{A. State-Space Model}

The assumptions to derive the model are: 1) the components are ideal and 2) the circuit is driven by frequency modulation. In this case, the control input is the angular switching frequency $\omega_{s}$.
This variable will be provided by the control system in order to reach the control objectives (i.e., output voltage regulation and operation under ZVS conditions). Under these assumptions and taking into account the equivalent circuits of the converter presented in [24], the differential state-space equations can be expressed as follows:

$$
\begin{aligned}
\frac{d i_{i}}{d t} & =\frac{1}{L_{i}}\left[V_{i}-\left(\frac{1+\operatorname{sgn}\left(\sin \omega_{s} t\right)}{2}\right) v_{c}\right] \\
\frac{d v_{c}}{d t} & =\frac{1}{C_{r}}\left[\left(\frac{1+\operatorname{sgn}\left(\sin \omega_{s} t\right)}{2}\right) i_{i}-i_{L}-\frac{n_{s}}{n_{p}} \operatorname{sgn}\left(v_{c}\right) i_{o}\right]
\end{aligned}
$$

$\frac{d i_{L}}{d t}=\frac{1}{L_{r}} v_{c}$

$\frac{d i_{o}}{d t}=\frac{1}{L_{o}}\left[\frac{n_{s}}{n_{p}}\left|v_{c}\right|-v_{o}\right]$

$\frac{d v_{o}}{d t}=\frac{1}{C_{o}}\left[i_{o}-\frac{v_{o}}{R}\right]$

where $i_{i}$ stands for the input current variable, $v_{c}$ and $i_{L}$ are the resonant state variables, and $v_{o}$ and $i_{o}$ are the output filter state variables. According to [32], the state-space variables can be divided in two subgroups: fast and slow variables. The resonant state variables are fast variables and evolve the following sinusoidal waveforms. Input current and output voltage and current are slow variables. They evolve slowly compared to the dynamics of resonant waveforms.

\section{B. Averaged Modeling of the Resonant State Variables}

The averaged method presented in [32] is used here to obtain a proper dynamic model. In this method, the resonant state variables are approximated as sinusoidal waveforms including slow time-varying amplitudes and phases, defined as

$$
\begin{aligned}
& v_{c}=V_{c} \sin \left(\omega_{s} t-\alpha\right) \\
& i_{L}=I_{L} \sin \left(\omega_{s} t-\beta\right)
\end{aligned}
$$

where $V_{c}$ and $I_{L}$ are the peak values of the resonant state vari- 143 ables, and $\alpha$ and $\beta$ are the initial phases. These variables are 144 then inserted into (2) and (3). By applying harmonic lineariza- 145 tion and harmonic balance to the resulting model, the following 146 equation is derived:

$$
\frac{d \bar{v}_{c}}{d t}=\frac{1}{C_{\text {eq }}}\left[\frac{m}{2} \overline{i_{i}}-\frac{n_{s}}{n_{p}} \bar{i}_{o}\right]
$$

where the symbol-denotes averaged value over a half-switching 148 cycle, and the equivalent capacitor $C_{\mathrm{eq}}$ and the new variable $m \quad 149$ can be expressed as

$$
\begin{aligned}
C_{\mathrm{eq}} & =\pi^{2} C_{r} / 8 \\
m & =\sqrt{1-\left[\frac{\pi^{2} Q}{4 R} \frac{\bar{v}_{c}}{\overline{i_{i}}}\left(\frac{\omega_{s}}{\omega_{o}}-\frac{\omega_{o}}{\omega_{s}}\right)\right]^{2}} .
\end{aligned}
$$

Note that $m$ is a variable that contains information about 151 the system state in an averaged sense (through the variables 152 $\bar{v}_{c}$ and $\bar{i}_{i}$ ) and the control action $\omega_{s}$. It is used here simply 153

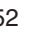


to compact the final expressions of the models. In (10), the variables $Q$ and $\omega_{0}$ represent the quality factor and angular resonant frequency of the resonant tank. In addition, $Z_{o}$ is the characteristic impedance. These variables are defined as

$$
\begin{aligned}
Q & =R / Z_{o} \\
\omega_{o} & =1 / \sqrt{L_{r} C_{r}} \\
Z_{o} & =\sqrt{L_{r} / C_{r}} .
\end{aligned}
$$

Further details on model derivation can be found in [33][35], where the averaged models of other resonant topologies have been derived. Note that, in this case, the resonant tank is described in an averaged sense because only one differential equation (8) models the dynamics of the averaged resonant capacitor voltage. This equation contains all the necessary information to reproduce the transient and steady-state behavior of the resonant tank in an averaged sense. Also, note that this equation is nonlinear.

\section{Averaged Modeling of Slow Variables}

The averaged dynamics of the slow variables, including the input and output state variables, are derived by using the timevarying averaging over a half-switching cycle, resulting in

$$
\begin{aligned}
& \frac{d \overline{i_{i}}}{d t}=\frac{1}{L_{i}} \cdot\left[V_{i}-\frac{m}{2} \bar{v}_{c}\right] \\
& \frac{d \bar{i}_{o}}{d t}=\frac{1}{L_{o}}\left[\frac{n_{s}}{n_{p}} \bar{v}_{c}-\bar{v}_{o}\right] \\
& \frac{d \bar{v}_{o}}{d t}=\frac{1}{C_{o}} \cdot\left[\bar{i}_{o}-\frac{\bar{v}_{o}}{R}\right] .
\end{aligned}
$$

Therefore, the complete averaged large-signal model of the class-D CSPRC is expressed by (8) and (14)-(16).

As far as authors know, the large signal model for the frequency-modulated CSPRC has not been previously studied. Hence, this model constitutes the first contribution of this paper. The accuracy of this model is validated in Section II-E by selected simulation results.

\section{Equilibrium Point}

In steady-state conditions, all the averaged variables reach their equilibrium point. By considering $d \overline{\mathrm{i}_{i}} / d t=0, d \overline{v_{c}} / d t=$ $0, d \overline{\mathrm{i}_{o}} / d t=0$, and $d \overline{v_{o}} / d t=0$, the equilibrium point of the model (8) and (14)-(16) can be expressed as

$$
\begin{aligned}
I_{i} & =\frac{V_{0}^{2}}{R V_{i}} \\
V_{c} & =\frac{2 V_{i}}{M} \\
I_{o} & =\frac{V_{o}}{R} \\
V_{o} & =\frac{n_{s}}{n_{p}} \frac{2 V_{i}}{M}
\end{aligned}
$$

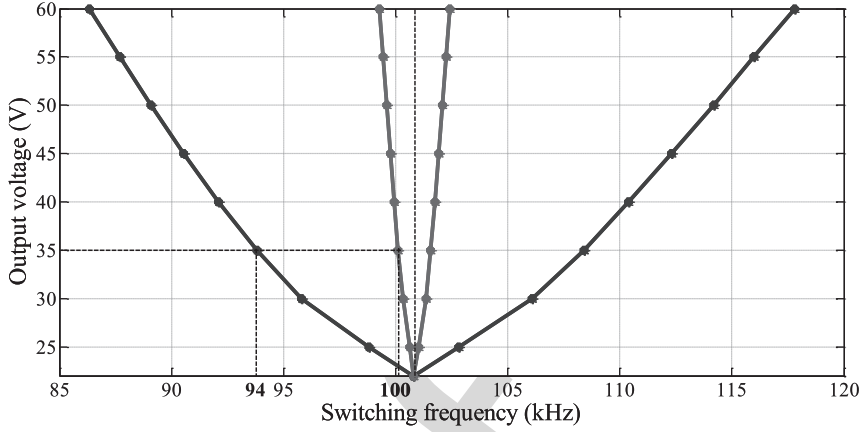

Fig. 2. Output voltage as a function of the switching frequency (FL in blue and $10 \%$ of FL in red).

TABLE I

VALUES OF THE POWER COMPONENTS

\begin{tabular}{llc}
\hline \hline Symbol & \multicolumn{1}{c}{ Quantity } & Value \\
\hline$V_{i}$ & Input voltage & $12 \mathrm{~V}$ \\
$L_{i}$ & Input filter inductor & $300 \mu \mathrm{H}$ \\
$C_{r}$ & Resonant capacitor & $470 \mathrm{nF}$ \\
$L_{r}$ & Resonant inductor & $5.3 \mu \mathrm{H}$ \\
$n_{p}: n_{s}$ & Transformer turns ratio & $1: 1$ \\
$L_{o}$ & Output filter inductor & $100 \mu \mathrm{H}$ \\
$C_{o}$ & Output filter capacitor & $470 \mu \mathrm{F}$ \\
$V_{o}$ & Output voltage & $35 \mathrm{~V}$ \\
$R$ & Full-load resistor & $20 \Omega$ \\
\hline \hline
\end{tabular}

where $M$ is the steady-state value of $m$ (i.e., the equilibrium 183 point of $m$ ), which can be written as

$$
\frac{1}{M}=\sqrt{1+\left[\frac{\pi^{2}}{8} Q\left(\frac{n_{s}}{n_{p}}\right)^{2}\left(\frac{\omega_{s}}{\omega_{o}}-\frac{\omega_{o}}{\omega_{s}}\right)\right]^{2}} .
$$

Note that the equilibrium point depends on the control input 185 $\omega_{s}$, the resonant circuit parameters, the input voltage, and the 186 load.

The output voltage in steady state can be easily determined from (20) and (21). Fig. 2 depicts this voltage as a function of the switching frequency for two load conditions: full load (FL) in blue and $10 \%$ of FL in red. The nominal values of the power components listed in Table I are used to draw the figure. Note that the output voltage can be maintained constant in steady state by adjusting conveniently the switching frequency. In fact, Fig. 2 also shows the theoretical values of the switching frequency that provides the nominal output voltage for the two considered load conditions.

\section{E. Validation of the Averaged Large-Signal Model}

The validity of the derived large-signal model expressed in (8) and (14)-(16) is evaluated by comparing selected simulation results with those obtained by the state-space model expressed in (1)-(5). Both models are implemented in MATLAB-Simulink, and the obtained results are shown in Fig. 3. Two different switching frequencies are considered to validate the averaged model in different operating points. During the first interval, the switching frequency is fixed at $91 \mathrm{kHz}$. At $t=10 \mathrm{~ms}$, the 


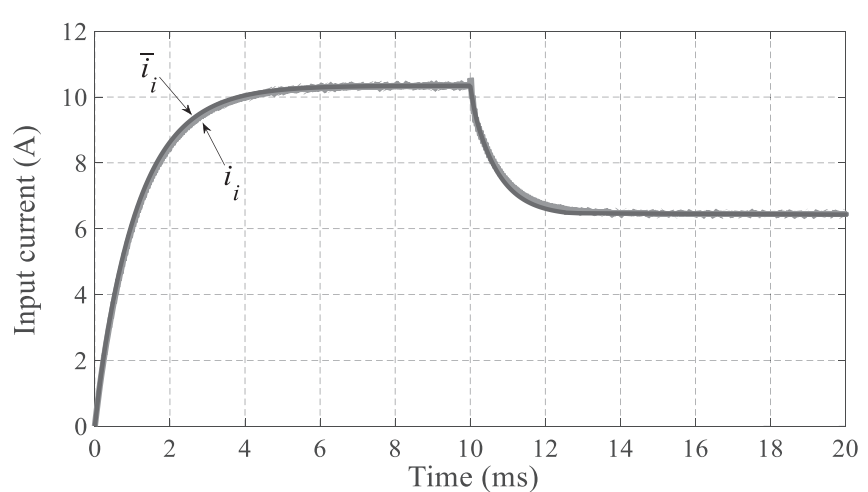

(a)

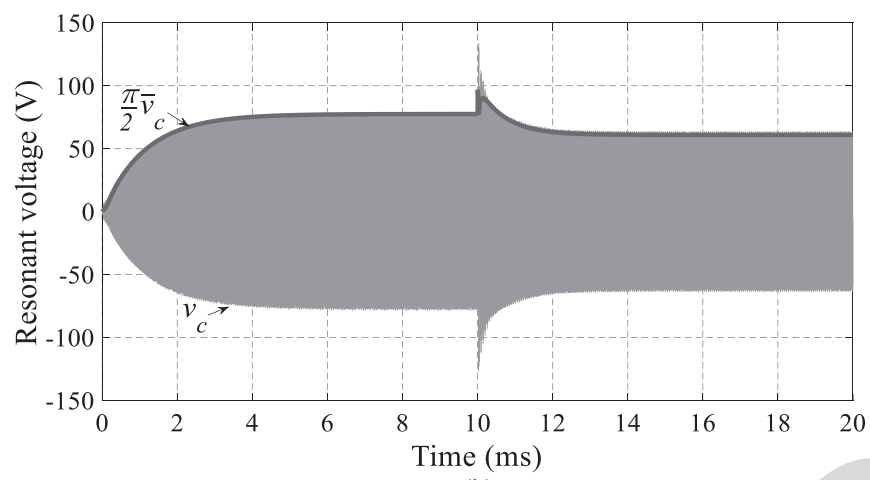

(b)

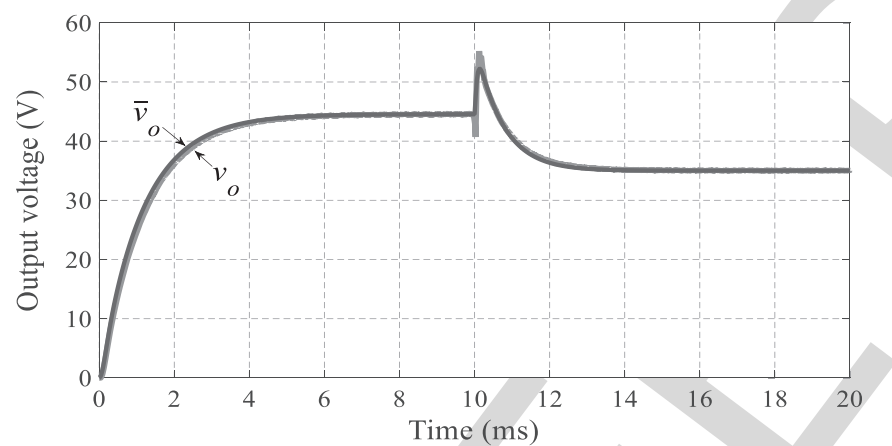

(c)

Fig. 3. Comparison of waveforms generated by the state-space model and the averaged large-signal model for two different switching frequencies $(0<t<10 \mathrm{~ms}: 91 \mathrm{kHz}, 10 \mathrm{~ms}<t<20 \mathrm{~ms}: 94 \mathrm{kHz})$ and FL condition: (a) input current, (b) resonant capacitor voltage, and (c) output voltage. switching frequency is changed to $94 \mathrm{kHz}$. This frequency is maintained to the end of the test. The results show good agreement between the models, although some small differences appear when the switching frequency is abruptly changed at $t=10 \mathrm{~ms}$. These mismatches are clearly caused by the assumptions made in the large-signal model derivation. However, for control design purposes, the observed high-frequency transients are not important due to the limited control bandwidth (BW).

\section{F. Small-Signal Model}

The small-signal model of the converter is derived by following the conventional approach based on perturbing and linearizing the large-signal model [36]. The systematic procedure is presented below. First, the state variables are decomposed in $\mathrm{dc}\left(I_{i}, V_{c}, I_{o}, V_{o}\right.$ and $M$, all defined in [17]-[20]) and ac $\left(\widehat{\mathrm{i}_{i}}, \widehat{\mathrm{v}_{c}}\right.$, $\widehat{\mathrm{i}_{o}}, \widehat{\mathrm{v}_{o}}$, and $\left.\widehat{m}\right)$ terms, given as follows:

220 221

$$
\begin{aligned}
& \bar{i}_{i}=I_{i}+\widehat{i_{i}} \\
& \bar{v}_{c}=V_{c}+\widehat{v_{c}} \\
& \overline{i_{o}}=I_{o}+\widehat{i}_{o} \\
& \bar{v}_{o}=V_{o}+\widehat{v}_{o} \\
& m=M+\hat{m} .
\end{aligned}
$$

Second, the amplitudes of the ac terms are considered 223 small in comparison to the dc quantities (obtained equilibrium 224 values), i.e.,

$$
\begin{aligned}
& \widehat{i_{i}} \ll I_{i} \\
& \widehat{v_{c}} \ll V_{c} \\
& \widehat{i_{o}} \ll I_{o} \\
& \widehat{v_{o}} \ll V_{o} \\
& \hat{m} \ll M .
\end{aligned}
$$

Third, by substituting (22)-(26) in (8) and (14)-(16), and tak- 226 ing into account that the products of two ac terms are negligible, 227 the small-signal model is derived. It can be written in matrix 228 form as follows:

$$
\begin{gathered}
{\left[\begin{array}{cccc}
s L_{i} & M & 0 & 0 \\
-M & s C_{\mathrm{eq}} & n_{s} / n_{p} & 0 \\
0 & -n_{s} / n_{p} & s L_{o} & 1 \\
0 & 0 & -1 & s C_{o}+(1 / R)
\end{array}\right]\left[\begin{array}{c}
\hat{i}_{i}(s) \\
\hat{v}_{c}(s) \\
\hat{i}_{o}(s) \\
\hat{v}_{o}(s)
\end{array}\right]} \\
=\left[\begin{array}{c}
-V_{c} \\
I_{i} \\
0 \\
0
\end{array}\right] \cdot \hat{m}(s)
\end{gathered}
$$

where $s$ is the Laplace operator. Note that all the transfer func- 230 tions that characterize the behavior of the converter in small 231 signal can be derived from (32).

The obtained small-signal model constitutes the second con- 233 tribution of this paper. This model is then utilized for control 234 design as explained in Section IV.

\section{Proposed Control Scheme}

This section introduces a control scheme for the parallel- 237 resonant converter with two possible configurations for the ex- 238 ternal voltage loop. The internal current loop and the FM are 239 also presented in detail.

\section{A. Voltage and Current Control Loops}

Fig. 4 shows the diagram of the proposed control scheme. It 242 is based on two control loops and an FM. The internal control 243 loop makes the system controllable and limits the input cur- 244 rent. To this end, it processes the input current error using a 245 


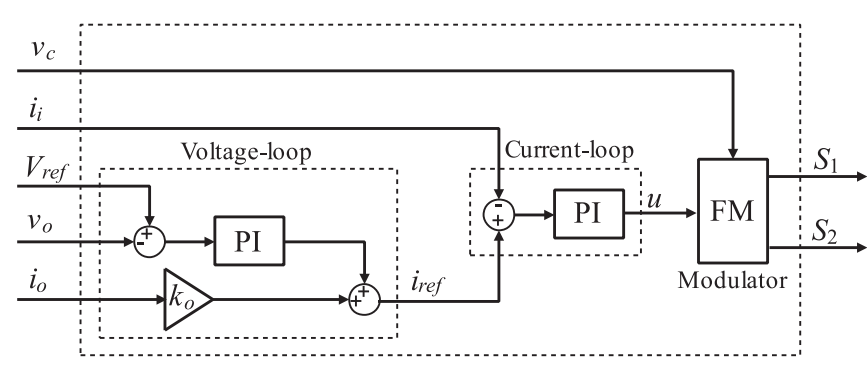

Fig. 4. Diagram of the two proposed control schemes. Basic configuration $\left(i_{o}\right.$ is not measured in this case and $\left.k_{o}=0\right)$ and enhanced configuration ( $i_{o}$ is measured in this case and $\left.k_{o}=V_{\mathrm{ref}} / V_{i}\right)$.

proportional-integral (PI) regulator and provides the signal $u$ to the input of the modulator.

The external voltage loop is responsible to regulate the output voltage. It has two control terms: a feedback term that tries to eliminate the output voltage error using a PI regulator and a feedforward term of the output current. The feedback term ensures that the output voltage matches the reference voltage in steady state, thus compensating the effects of unmodeled elements such as parasitic resistors and transformer leakage inductances. In the case of load-step changes, the feed-forward term helps the modulator to rapidly find an appropriate switching frequency to ensure a fixed-output voltage, yielding in a fast transient response.

The proposed controller is called here basic configuration when $k_{o}=0$ and enhanced configuration when $k_{o}=I_{i} / I_{o}$. In the enhanced controller, the steady-state currents in the feedforward gain $k_{o}$ rely on the load condition. However, from (18) and (20) and assuming $V_{o}=V_{\text {ref }}$, the feed-forward gain is independent of the load condition and can be written as

$$
k_{o}=\frac{V_{\mathrm{ref}}}{V_{i}}
$$

The enhanced controller is introduced in order to improve the transient response, i.e, to get a negligible output voltage deviation and lower settling time. This is considered as the benefit of this control configuration. However, an additional measurement $i_{o}$ is required in this case, slightly increasing the cost of the system.

\section{B. Frequency Modulator}

This section proposes an FM for the CSPRC. The modulator is derived from the phase modulator presented in [37] for voltage-source resonant converters. The differences between both modulators are also highlighted below.

Fig. 5(a) shows the proposed FM. It is based on the generation of a saw-tooth waveform synchronized by the zero crossing detection of the resonant capacitor voltage. This waveform is then compared with the output signal of the controller $u$ in order to generate the gate signals $\left(S_{1}\right.$ and $\left.S_{2}\right)$ by using an RS flip-flop. Fig. 5(b) shows the main waveforms of the modulator. Note that the switching period depends on the load conditions, as predicted by (21). It is worth mentioning that the ramp amplitude is always one in this modulator in order to modify the

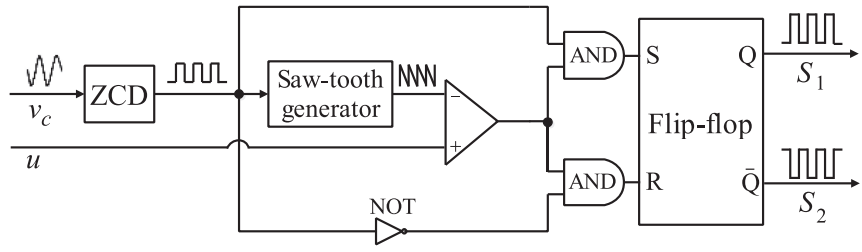

(a)

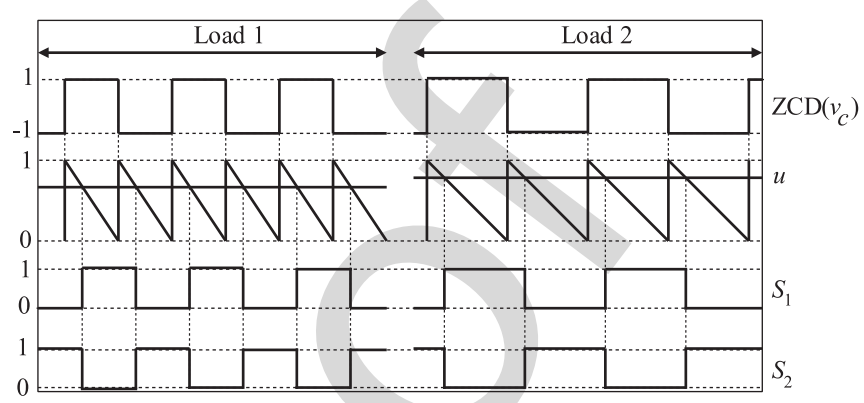

(b)

Fig. 5. Proposed FM including a variable slope, fixed amplitude sawtooth generator: (a) diagram and (b) main waveforms for two different load conditions.

switching period as a function of the load condition. The sawtooth generator produces this distinctive feature by means of a closed-loop control using a PI regulator; see details in [37]. The most promising feature of both modulators is the high robustness to resonant parameter variations. This feature is attributed to the sensing of the resonant tank state, through the measure of a resonant state variable. Thus, changes on resonant components due to temperature, tolerance, age, etc., are perfectly absorbed by the modulator. The main differences between the two modulators are as follows.

1) The resonant capacitor voltage instead of the inductor current is used to provide ZVS conditions.

2) The slope of the ramp signal is reversed to operate below resonance (the voltage-source resonant converter operates above resonance).

3) Only one input signal $u$ is required to regulate the output voltage (the phase modulator needs two signals).

The proposed control scheme is the third contribution of this paper. The novelties of this configuration are: first, the feedforward term included in the conventional two loop control in order to accelerate the transient response during load step changes; and second, the adaptive modulator used to synchronize the control action with the zero crossing of the resonant capacitor voltage, thus providing ZVS condition. In addition, the modulator provides a robust operation against internal and external disturbances (such as variations in resonant tank parameters and input voltage, respectively).

\section{CONTROL DESIGN}

This section presents the design procedure to obtain the gains of the two PI controllers used in the proposed control scheme. A numerical example is also included to illustrate the procedure in detail. This design procedure constitutes the fourth contribution 


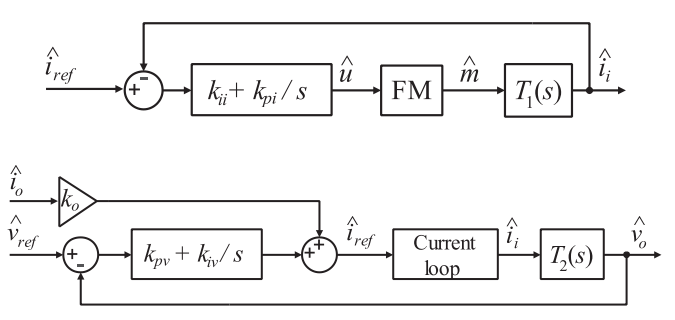

Fig. 6. Small-signal diagram of the (a) internal control loop and (b) external control loop.

of this paper. A numerical example is also included to illustrate the procedure in detail.

\section{A. Design Procedure}

The control design proceeds as follows.

1) The closed-loop transfer functions of the system are first obtained by using the derived small-signal model.

2) The frequency-domain specifications of the closed-loop system are fixed in terms of desired control BW and phase margin (PM).

3) The gain values of the PI controllers satisfying the specifications are selected.

To this end, Bode diagrams of different set of gain values are examined until the specifications are met.

\section{B. Closed-Loop Small-Signal Models}

Fig. 6 shows the small-signal diagram of the internal and external control loops. Note that the two PI controllers are included in the figure. The other transfer functions involved in the diagram are derived below.

The control to input-current $T_{1}(s)$ and input-current to outputvoltage $T_{2}(s)$ transfer functions are obtained from the smallsignal model expressed in (24). These transfer functions are

$$
\begin{aligned}
& T_{1}(s)=\frac{\hat{i}_{i}(s)}{\hat{m}(s)}=\frac{A_{1} s^{3}+A_{2} s^{2}+A_{3} s+A_{4}}{B_{1} s^{4}+B_{2} s^{3}+B_{3} s^{2}+B_{4} s+B_{5}} \\
& T_{2}(s)=\frac{\hat{v}_{o}(s)}{\hat{i}_{i}(s)}=\frac{C_{1} s+C_{2}}{B_{1} s^{4}+B_{2} s^{3}+B_{3} s^{2}+B_{4} s+B_{5}} .
\end{aligned}
$$

The coefficients of these transfer functions can be found in the Appendix.

The transfer function of the proposed modulator is deduced according to the following points and assumptions.

1) It is well known that the small-signal model of a modulator involving a ramp signal coincides with the inverse of the amplitude of this signal (i.e., $1 / V_{\text {ramp }}$ ) [36].

2) In the proposed modulator, a closed-loop control is used in the saw-tooth generator to fix the amplitude of the ramp signal to one $\left(V_{\text {ramp }}=1\right)$.

3) This control loop is fast enough compared to the BW of the internal and external control loops.

Thus, the transfer function of the modulator can be expressed as

$$
\frac{\hat{m}}{\hat{u}}=\frac{1}{V_{\text {ramp }}}=1 .
$$

TABLE ॥

FREQUENCY-DOMAIN SPECIFICATIONS

\begin{tabular}{lcc}
\hline \hline Control loops & BW $(\mathrm{kHz})$ & $\mathrm{PM}\left({ }^{\circ}\right)$ \\
\hline Current loop & 7.467 & 60 \\
Voltage loop & 0.593 & 60 \\
\hline \hline
\end{tabular}

TABLE III

VAlues of the Control Gains and Parameters

\begin{tabular}{llc}
\hline \hline Symbol & \multicolumn{1}{c}{ Quantity } & Value \\
\hline$k_{p i}$ & Current-loop proportional gain & $0.4 \mathrm{~A}^{-1}$ \\
$k_{i i}$ & Current-loop integral gain & $30 \mathrm{~Hz} / \mathrm{A}$ \\
$k_{p v}$ & Voltage-loop proportional gain & $0.01 \Omega^{-1}$ \\
$k_{i v}$ & Voltage-loop integral gain & $120 \mathrm{~Hz} / \Omega$ \\
$k_{o}$ & Feed-forward gain (basic control) & 0 \\
$k_{o}$ & Feed-forward gain (enhanced control) & 2.9 \\
$V_{\text {ref }}$ & Reference output voltage & $35 \mathrm{~V}$ \\
\hline
\end{tabular}

The design of the PI controllers is based on making the dy- 352 namic characteristics meet the control design specifications. 353

Table II lists these specifications for the internal and external 354 control loops. In the internal current loop, the control BW is 355 1.1 decades below the minimum switching frequency to get a 356 fast current transient response. In the external voltage loop, the 357 control BW is 1.1 decades below the control BW specification of 358 the current loop in order to avoid undesired interactions between 359 these control loops. The PMs are high enough to prevent the 360 converter from going to the instability region.

The dynamic characteristics of the CSPRC can be extracted 362 from the current and voltage loop gains. From Fig. 6, these 363 transfer functions can be written as

$$
\begin{aligned}
T_{i}(s) & =\left[k_{p i}+\frac{k_{i i}}{s}\right] T_{1}(s) \\
T_{v}(s) & =\left[k_{p v}+\frac{k_{i v}}{s}-\frac{k_{o}}{R}\right] T_{2}(s) .
\end{aligned}
$$

Note that the loop gains depend directly on the gains of the 365 two PI controllers, as usual. In the voltage loop gain, a perfect 366 tracking of the reference current is assumed, i.e., $\hat{i}_{i}(s) / \hat{i}_{\text {ref }}(s)=367$ 1. This is actually a good approximation due to the reduced 368 control BW of the voltage loop. In addition, the feed-forward 369 term $k_{0}$ appears in the voltage loop gain, so that the dynamic 370 characteristics will be analyzed for: the current loop, the basic 371 voltage loop $\left(k_{o}=0\right)$, and the enhanced voltage loop $\left(k_{o}=372\right.$ $V_{\text {ref }} / V_{i}$ ). Hence, the impact of $k_{o}$ on the transient response will 373 be also analyzed considering the closed-loop transfer function 374 shown in (38), derived from the small-signal model.

\section{Design of the Internal and External Control Loops}

The values of the PI gains are obtained according to the 377 design specifications. Several Bode diagrams are represented 378 with different PI gains until the specifications are met. Once 379 this process is finished, the final values of the PI gains are 380 captured and listed in Table III. The values of the feed-forward 381 


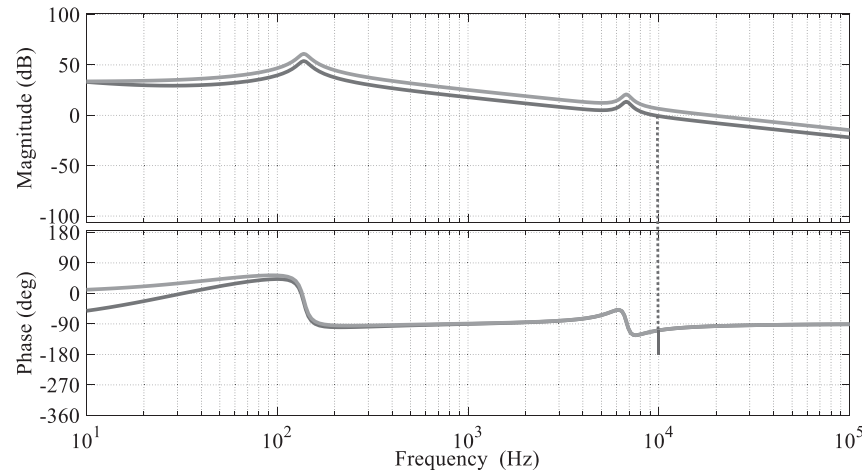

(a)

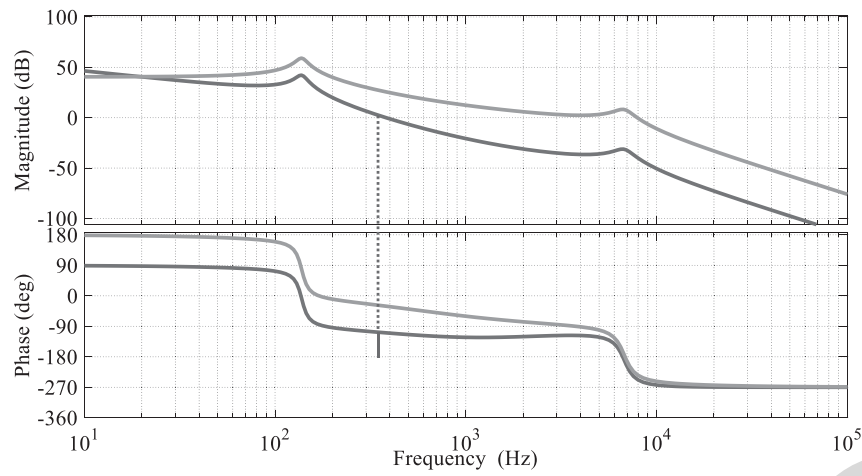

(b)

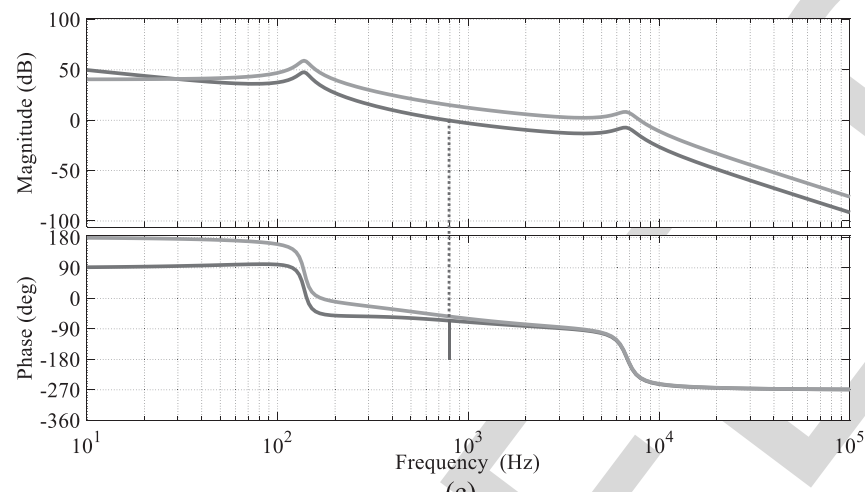

(c)

Fig. 7. Bode diagrams of (a) current loop gain, (b) voltage loop gain for the basic control $\left(k_{o}=0\right)$, and (c) voltage loop gain for the enhanced control $\left(k_{o}=V_{\text {ref }} / V_{i}\right)$ for FL condition (blue: compensated and orange: uncompensated). gains for the basic and the enhanced control configurations are also included in the table. Fig. 7 shows the Bode diagram of the loop gains for both compensated and uncompensated system at FL condition. Note that the compensated system reduces the control BW to reach the design specifications, as depicted in Fig. 7.

For the current loop, the control BW is $9.43 \mathrm{kHz}$ and the PM is $67.1^{\circ}$, meeting satisfactorily the design specifications. In the basic voltage loop, although the PM is good enough $\left(70.4^{\circ}\right)$, the control BW $(0.35 \mathrm{kHz})$ is lower than the specification. Thanks to the feed-forward term, the enhanced voltage loop shows superior performance by increasing both the control BW $(0.81 \mathrm{kHz})$ and the PM $\left(116.4^{\circ}\right)$. The design specifications are clearly meet by the enhanced control configuration.
TABLE IV

DYNAMIC CHARACTERISTICS FOR DIFFERENT LOAD CONDITIONS

\begin{tabular}{|c|c|c|c|c|c|}
\hline \multirow[t]{2}{*}{ Control scheme } & \multirow[t]{2}{*}{ Load condition } & \multicolumn{2}{|c|}{ Current loop } & \multicolumn{2}{|c|}{ Voltage loop } \\
\hline & & $\mathrm{BW}(\mathrm{kHz})$ & $\operatorname{PM}\left(^{\circ}\right)$ & $\mathrm{BW}(\mathrm{kHz})$ & $\mathrm{PM}\left({ }^{\circ}\right)$ \\
\hline Basic & FL & 9.43 & 67.1 & 0.35 & 70.4 \\
\hline$\left(k_{o}=0\right)$ & $10 \%$ of FL & 8.52 & 85.2 & 0.23 & 98.2 \\
\hline Enhanced & FL & 9.43 & 67.1 & 0.81 & 116.4 \\
\hline$\left(k_{o}=V_{\mathrm{ref}} / V_{i}\right)$ & $10 \%$ of FL & 8.52 & 85.2 & 0.67 & 153.3 \\
\hline
\end{tabular}

TABLE V

PROTOTYPE COMPONENTS

\begin{tabular}{lc}
\hline \hline Component & Model \\
\hline Diodes & 20ETF08S \\
MOSFETs & IRFR4620 \\
MOSFET driver & MCP14E10 \\
Resonant capacitor & MKT type \\
Op-amps & MCP6022 \\
\hline \hline
\end{tabular}

Table IV shows the dynamic characteristics for different load conditions. Note that the control BW improves as the load increases for both control loops. Conversely, the PM deteriorates as the load increases. Anyway, the design specifications are meet for the current loop and the enhanced voltage loop. In addition, the enhanced voltage loop improves the dynamic characteristics of the basic voltage loop for all load conditions.

\section{EXPERIMENTAL RESULTS}

This section validates the proposed control scheme with selected experimental results from a laboratory prototype.

\section{A. Laboratory Prototype}

A $60-\mathrm{W}$ laboratory prototype was built including a dcdc class-D CSPRC with a SPIC33FJ16GS504-I/PT microcontroller as digital control platform. The input and output currents were sensed with current transducers (LTP-15NP). Simple ana$\log$ circuits including differential amplifiers are used to sense the resonant capacitor and output voltages. Other prototype components are listed in Table V. Fig. 8 shows the top and bottom views of the laboratory prototype.

\section{B. Evaluation of Static Characteristics}

In this section, the steady-state operation of the CSPRC is evaluated.

Fig. 9 shows the steady-state voltage across the right leg of the class-D inverter shown in Fig. 1 (including the voltages in MOSFET S2 and blocking diode D2) and its associated current for both FL and $10 \%$ of FL. Note that the waveform of the switch voltage is similar in both load conditions. The only notable difference is a change in the switching frequency. However, in the switch current waveform, the change in both switching frequency and in amplitude is observed. These features were theoretically predicted by (18)-(21), as discussed in Section V-C. 


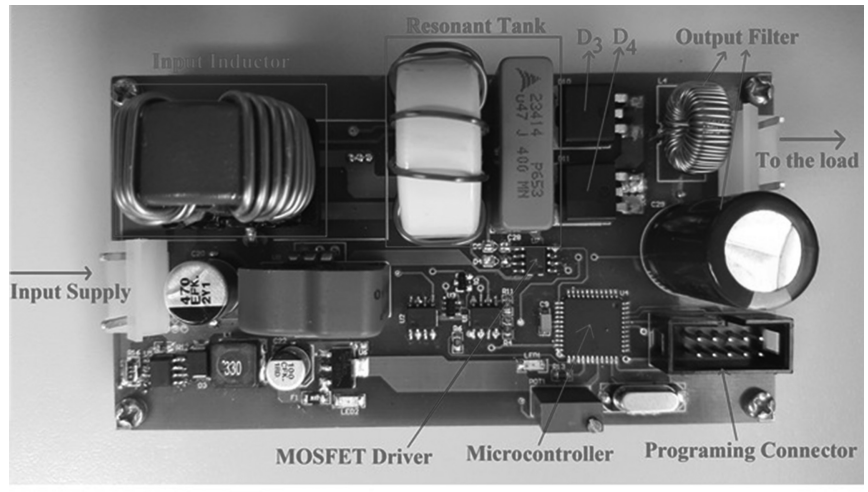

(a)

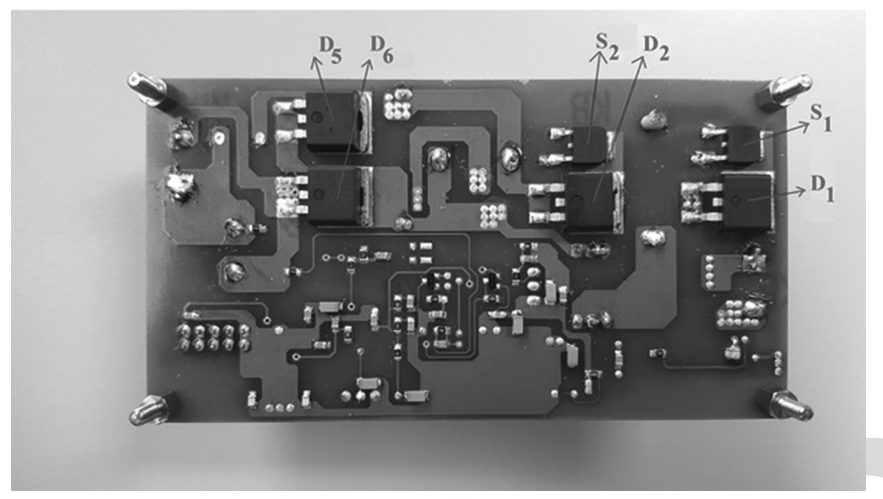

(b)

Fig. 8. Experimental dc-dc CSPRC prototype: (a) top view and (b) bottom view.

Fig. 9 also reveals the ZVS operation of the CSPRC. When the switch is OFF (interval with zero switch current), the switch voltage tracks the resonant capacitor voltage by changing sinusoidally from positive to negative values. In the interval with negative values, the diode D2 is naturally in OFF state and then MOSFET S2 can be driven to ON state. In this case, although S2 is ON, no current flows through the switch due to the blocking diode D2. Thus, the MOSFET S2 is in ON state with zero voltage across before switch current increases during the switch transition from OFF to ON. This mechanism is known as ZVS operation and is characterized by negligible switching losses.

Fig. 10 shows the system efficiency as a function of the output power. The highest efficiency (95\%) is obtained at $55 \mathrm{~W}(90 \%$ of full power). As usual, the efficiency deteriorates as output power reduces, being $91.1 \%$ the lowest efficiency measured at $15 \mathrm{~W}$ ( $25 \%$ of full power).

\section{Evaluation of Dynamic Characteristics}

Fig. 11(a) shows the transient response of the output voltage during load step changes using the basic control configuration. Note that the load changes produce significant voltage deviations and large settling times. Fig. 11(b) depicts the transient response of the resonant capacitor voltage, showing a similar dynamic. Note that the steady-state amplitude of the resonant capacitor voltage is constant, independent of the load. This fact was predicted theoretically by (18), (20), and (21). The

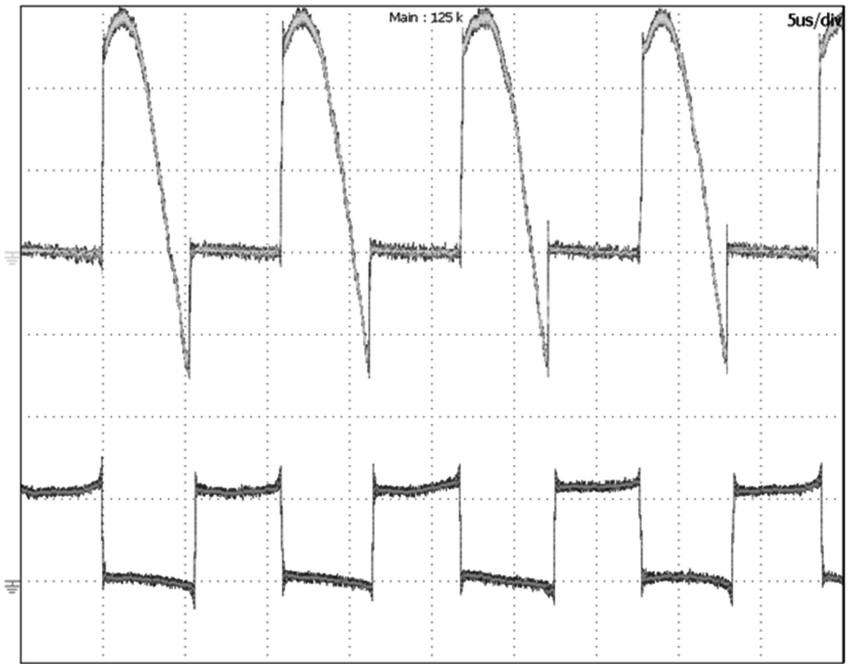

(a)

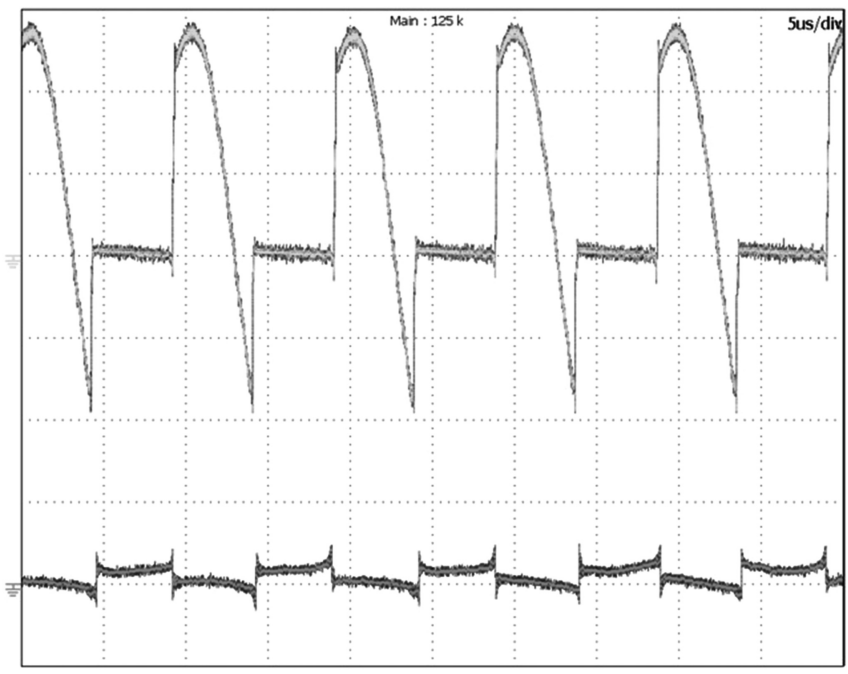

(b)

Fig. 9. Steady-state switch voltage (green, $20 \mathrm{~V} / \mathrm{div}, 5 \mu \mathrm{s} / \mathrm{div}$ ) and current (pink, $5 \mathrm{~A} /$ div) for: (a) FL and (b) $10 \%$ of FL.

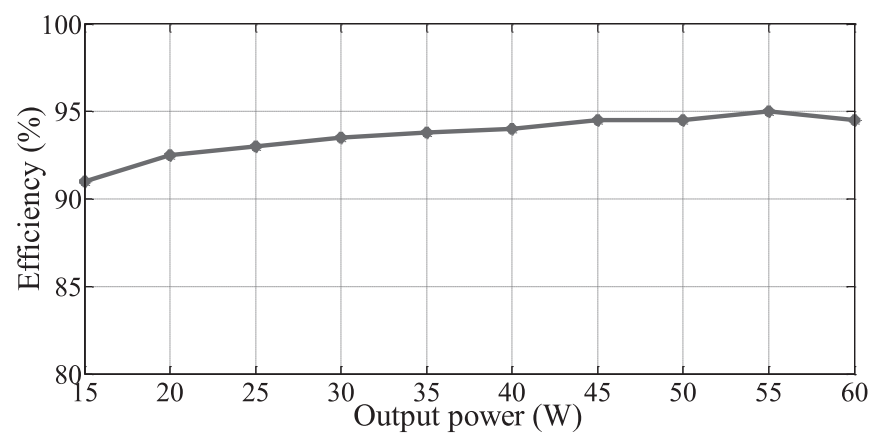

Fig. 10. System efficiency as a function of output power.

control scheme modifies the switching frequency when the load 452 changes to maintain $M$ constant in steady state; see (21). By this 453 mechanism, the output voltage and the amplitude of the reso- 454 nant capacitor voltage are constants in steady state, as observed 455 in (18) and (20). Conversely, the input and output currents rely 456 


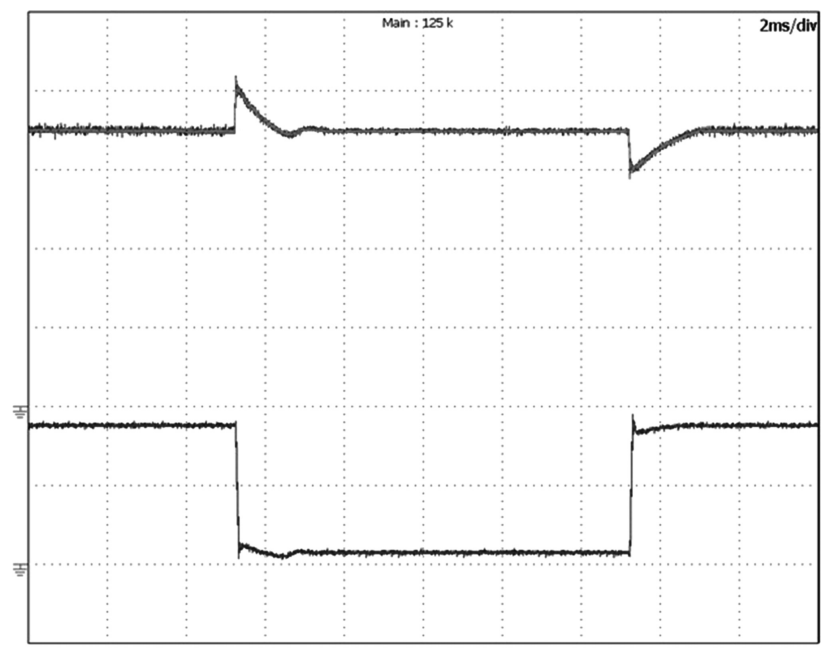

(a)

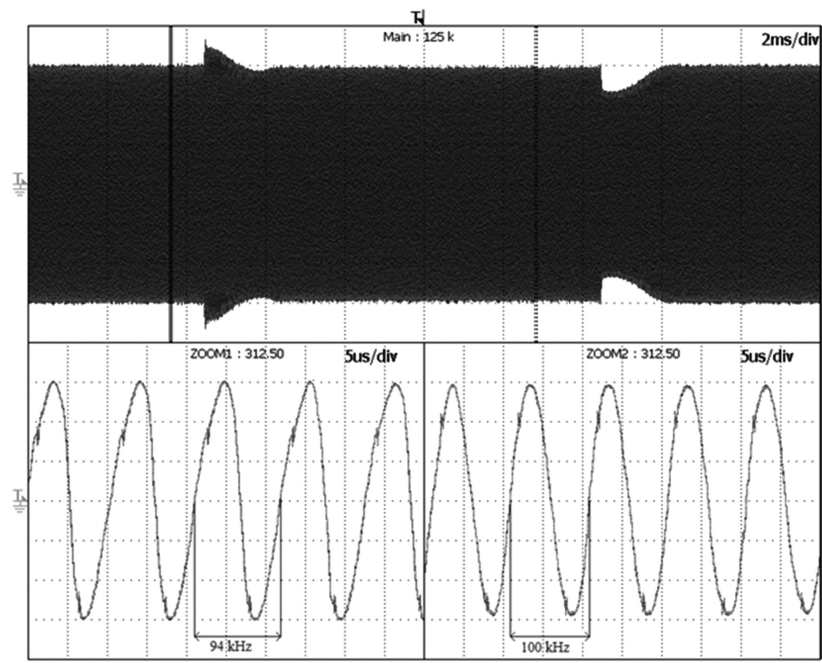

(b)

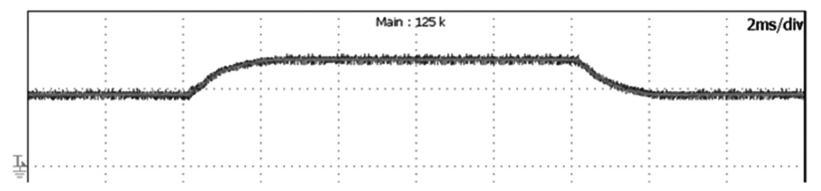

(c)

Fig. 11. Load transient response of the basic control configuration $\left(k_{o}=0\right)$ : (a) output voltage (red, $\left.10 \mathrm{~V} / \mathrm{div}, 2 \mathrm{~ms} / \mathrm{div}\right)$ and current (blue, $1 \mathrm{~A} /$ div), (b) resonant capacitor voltage (20 V/div, $2 \mathrm{~ms} / \mathrm{div}), v_{c}$ zoom (5 $\mu \mathrm{s} /$ div), and (c) signal $u$ (2 V/div, $2 \mathrm{~ms} / \mathrm{div})$. on the load condition, as predicted by (17) and (19). The areas marked in Fig. 11(b) have been zoomed-in and shown in the lower side of this figure. As it can be seen, the switching frequency increases from 94 to $100 \mathrm{kHz}$ to regulate the output voltage when the load changes from FL to $10 \%$ of FL. These experimental measures are well matched with the theoretical results shown in Fig. 2. It is interesting to observe that the quality of the resonant waveforms improves when the switching frequency approaches the resonant frequency. Furthermore, modulator $(u)$. Note that the basic control has slow dynamics with a settling time around $2 \mathrm{~ms}$. Fig. 11(c) shows the transient response of the input signal of the

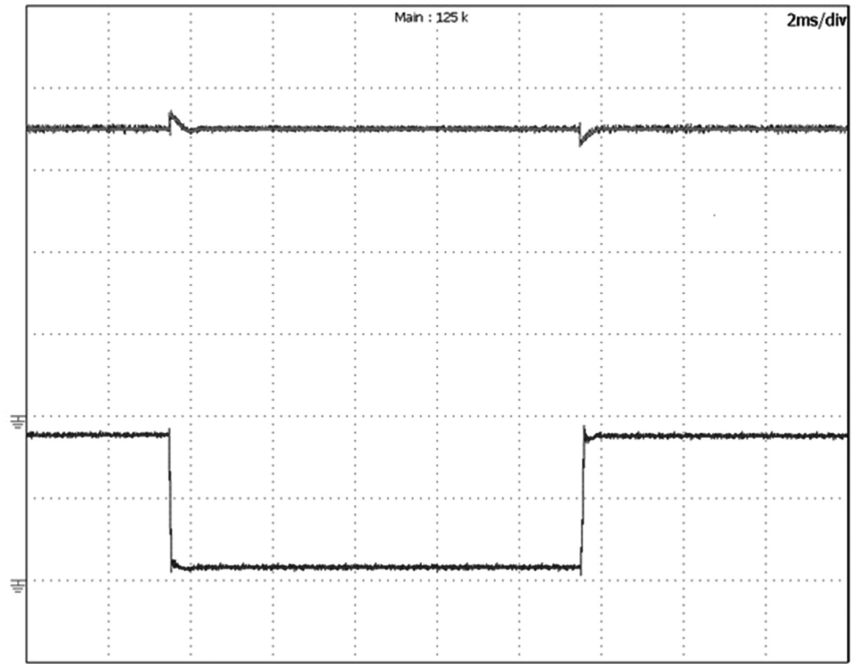

(a)

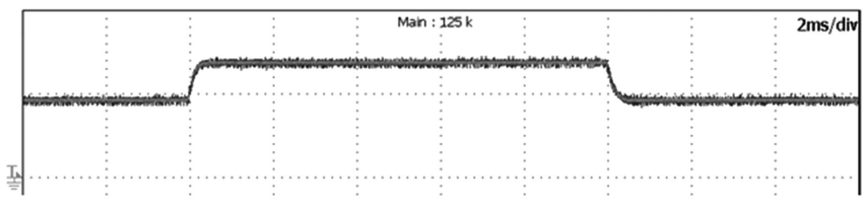

(b)

Fig. 12. Load transient response of the enhanced control configuration $\left(k_{o}=V_{\text {ref }} / V_{i}\right)$ : (a) output voltage (red, $10 \mathrm{~V} /$ div, $2 \mathrm{~ms} /$ div) and current (blue, $1 \mathrm{~A} / \mathrm{div})$, and (b) signal $u(2 \mathrm{~V} / \mathrm{div}, 2 \mathrm{~ms} / \mathrm{div})$.

Fig. 12(a) shows the transient response of the output voltage 469 during load changes using the enhanced control. As predicted 470 by Fig. 7(c) and Table IV, the transient response is drastically 471 improved. In fact, the voltage overshoots and setting times are 472 clearly reduced from 5 to $1 \mathrm{~V}$ and from 1.8 to $0.4 \mathrm{~ms}$, respec- 473 tively. These enhancements are the consequence of the transient 474 response improvement in the input signal of the modulator $(u), \quad 475$ as depicted in Fig. 12(b). It means that in the case of load-step 476 changes, the feed-forward term helps the modulator to rapidly 477 find an appropriate switching frequency to ensure a fixed-output 478 voltage.

The load transient response is also evaluated for different values of the input voltage. Fig. 13 shows the results for $V_{i}=$ $10 \mathrm{~V}$ and Fig. 14 for $V_{i}=14 \mathrm{~V}$. Note that the voltage deviations during load changes reduce as the input voltage increases (i.e., when the gain of the converter reduces).

In any case, the most important issue is that the dynamic behavior of the enhanced control is still superior than the performance of the basic control for any value of the input voltage; compare Figs. 11-14. In particular, the transient response is faster with lower voltage deviations and settling times (benefit of the enhanced control), as expected from the theoretical analysis.

However, the drawback associated to the enhanced control is the additional measurement $\left(i_{o}\right)$ required to implement the feed-forward term, increasing the overall cost of the system. Therefore, regarding the desired performance and cost, one of the two proposed control configurations should be applied to the converter.

\section{9} 470 71 72 43

47

75

476

77
48




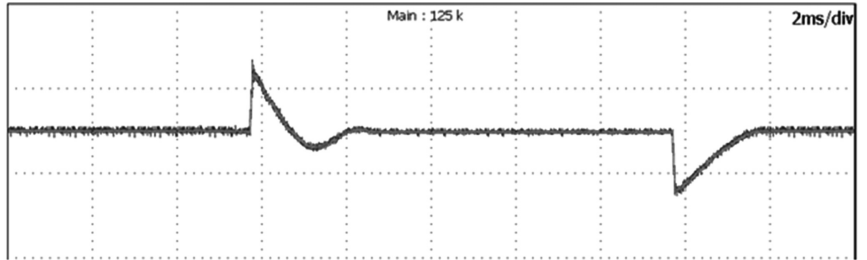

(a)

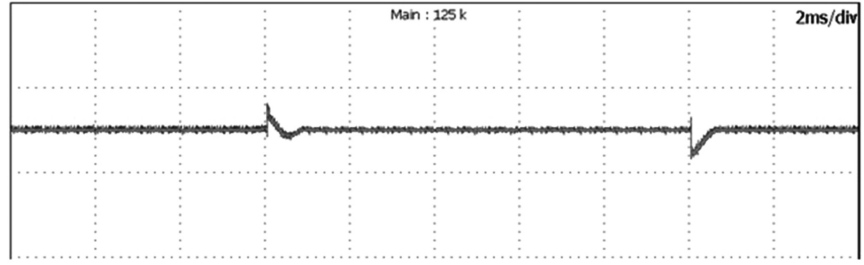

(b)

Fig. 13. Load transient response for $V_{i}=10 \mathrm{~V}$ and $V_{\text {ref }}=35 \mathrm{~V}$. (a) Basic control configuration $\left(k_{o}=0\right)$. (b) Enhanced control configuration $\left(k_{o}=V_{\text {ref }} / V_{i}\right)$. $10 \mathrm{~V} /$ div, $2 \mathrm{~ms} /$ div.

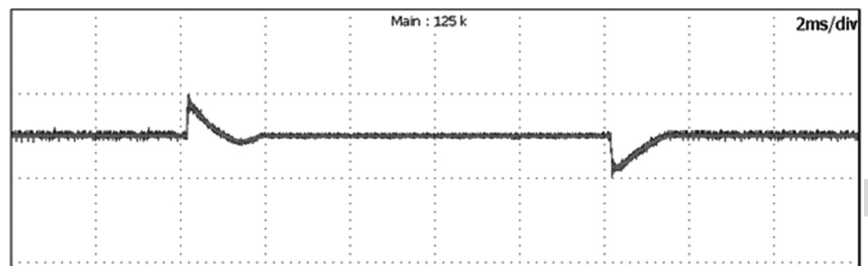

(a)

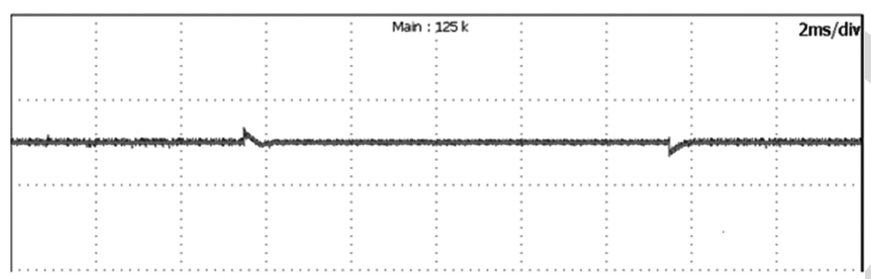

(b)

Fig. 14. Load transient response for $V_{i}=14 \mathrm{~V}$ and $V_{\text {ref }}=35 \mathrm{~V}$. (a) Basic control configuration $\left(k_{o}=0\right)$. (b) Enhanced control configuration $\left(k_{o}=V_{\text {ref }} / V_{i}\right)$. $10 \mathrm{~V} /$ div, $2 \mathrm{~ms} /$ div. modifying the logic circuit of the modulator. The proposed control configurations were promising closed-loop control systems to be employed in switching power supplies. The extension to other applications was left for future research work.

\section{APPENDIX}

This Appendix shows the coefficients of the transfer functions expressed in (34) and (35)

$$
\begin{aligned}
& A_{1}=V_{c}+I_{i} M R \\
& A_{2}=C L_{o} V_{c}+C_{o} I_{i} L_{o} M R \\
& A_{3}=I_{i} L_{o} M+C R V_{c}+C_{o} R V_{c} \\
& A_{4}=V_{c}+I_{i} M R \\
& B_{1}=C C_{o} L_{i} L_{o} R \\
& B_{2}=C L_{i} L_{o} \\
& B_{3}=C L_{i} R+C_{o} L_{i} R+C_{o} L_{o} M^{2} R \\
& B_{4}=L_{i}+L_{o} M^{2} \\
& B_{5}=M^{2} R \\
& C_{1}=I_{i} M R L_{i} \\
& C_{2}=-R M V_{c} .
\end{aligned}
$$

\section{REFERENCES}

[1] H. Sarnago, O. Lucia, A. Mediano, and J. M. Burdio, "Modulation scheme for improved operation of an RB-IGBT-based resonant inverter applied to domestic induction heating," IEEE Trans. Ind. Electron., vol. 60, no. 5, pp. 2066-2073, May 2013.

[2] W. Li, H. Zhao, S. Li, J. Deng, T. Kan, and C. C. Mi, "Integrated LCC 528 compensation topology for wireless charger in electric and plug-in electric 529 vehicles," IEEE Trans. Ind. Electron., vol. 62, no. 7, pp. 4215-4225, 530 Jul. 2015.

[3] Y. Wang, Y. Guan, K. Ren, W. Wang, and D. Xu, “A single-stage LED 532 driver based on BCM boost circuit and LLC converter for street light- 533 ing system," IEEE Trans. Ind. Electron., vol. 62, no. 9, pp. 5446-5457, 534 Sep. 2015.

[4] Y. Tang and A. Khaligh, "Bidirectional resonant DC-DC step-up convert- 536 ers for driving high-voltage actuators in mobile microrobots," IEEE Trans. 537 Power Electron., vol. 31, no. 1, pp. 340-352, Jan. 2016.

[5] O. Lucia, J. M. Burdio, I. Millan, J. Acero, and D. Puyal, "Load adap- 539 tive control algorithm of half-bridge series resonant inverter for do- 540 mestic induction heating," IEEE Trans. Ind. Electron., vol. 56, no. 8, 541 pp. 3106-3116, Aug. 2009

[6] K. Yan, Q. Chen, J. Hou, X. Ren, and X. Ruan, "Self-oscillating contactless resonant converter with phase detection contactless current transformer," IEEE Trans. Power Electron., vol. 29, no. 8, pp. 4438-4449, Aug. 2014.

[7] A. Moradewicz and P. Kazmierkowski, "Novel FPGA based control of series resonant converter for contactless power supply," in Proc. EUROCON, 2007, pp. 1328-1335. mode control for a multiple-user inductive power transfer system withou need for communication," IEEE Trans. Ind. Electron., vol. 60, no. 1, pp. 271-279, Jan. 2013.

[9] P. Xuewei and A. K. Rathore, "Novel bidirectional snubberless naturally commutated soft-switching current-fed full-bridge isolated DC/DC converter for fuel cell vehicles," IEEE Trans. Ind. Electron., vol. 61, no. 5 , pp. 2307-2315, May 2014. S. S. Lee, S. Iqbal, and M. Kamarol, "Control of ZCS-SR inverter-fed 557 voltage multiplier-based high-voltage DC-DC converter by digitally tun- 558 ing tank capacitance and slightly varying pulse frequency," IEEE Trans. 559 Power Electron., vol. 27, no. 3, pp. 1076-1083, Mar. 2012.

[11] K. R. Sree and A. K. Rathore, "Impulse commutated zero-current switch- 561 ing current-fed push-pull converter: Analysis, design, and experimental 562 results," IEEE Trans. Ind. Electron., vol. 62, no. 1, pp. 363-370, Jan. 2015.563 
[12] S. Iqbal, G. K. Singh, and R. Besar, "A dual-mode input voltage modulation control scheme for voltage multiplier based X-ray power supply," IEEE Trans. Power Electron., vol. 23, no. 2, pp. 1003-1008, Mar. 2008.

[13] M. A. Halim, M. N. Hidayat, and M. N. Seroji, "Implementation and analysis of a half-bridge series-parallel LLC loaded resonant DC-DC converter for low power applications," in Proc. IEEE Power Electron. Drive Syst., 2013, pp. 634-638.

[14] D. Reusch and J. Strydom, "Evaluation of gallium nitride transistors in high frequency resonant and soft-switching DC-DC converters," IEEE Trans. Power Electron., vol. 30, no. 9, pp. 5151-5158, Sep. 2015.

[15] X. Zhang, T. C. Green, and A. Junyent-Ferré, "A new resonant modular multilevel step-down DC-DC converter with inherent-balancing," IEEE Trans. Power Electron., vol. 30, no. 1, pp. 78-88, Jan. 2015.

[16] J. T. Boys, G. A. Covic, and A. W. Green, "Stability and control of inductively coupled power transfer system," Proc. Inst. Elect. Eng.-Elect. Power Appl., vol. 147, no. 1, pp. 37-43, Jan. 2000.

[17] M. G. Kim and M. J. Youn, "An energy feedback control of series resonant converters," IEEE Trans. Power Electron., vol. 6, no. 4, pp. 338-345, Jul. 1991.

[18] D. J. Tschirhart and P. K. Jain, "A CLL resonant asymmetrical pulse width modulated converter with improved efficiency," IEEE Trans. Ind. Electron., vol. 55, no. 1, pp. 114-122, Jan. 2008.

[19] V. Esteve, "Improving the efficiency of IGBT series resonant inverters using pulse density modulation," IEEE Trans. Ind. Electron., vol. 58, no. 3, pp. 979-987, Mar. 2011

[20] L. A. Barragan, D. Navarro, J. Acero, I. Urriza, and J. M. Burdio, "FPGA implementation of a switching frequency modulation circuit for EMI reduction in resonant inverters for induction heating appliances," IEEE Trans. Ind. Electron., vol. 55, no. 1, pp. 11-20, Jan. 2008.

[21] J. M. Carrasco, E. Galván, G. E. Valderrama, R. Ortega, and A. Stankovic, "Analysis and experimentation of nonlinear adaptive controllers for the series resonant converter,' IEEE Trans. Power Electron., vol. 15, no. 3, pp. 536-544, May 2000.

[22] M. Castilla, L. García de Vicuña, M. López, O. López, and J. Matas, "On the design of sliding mode control schemes for quantum resonant converters," IEEE Trans. Power Electron., vol. 15, no. 6, pp. 960-973, Nov. 2000.

[23] I. H. Cho, Y. D. Kim, and G. W. Moon, "A half-bridge LLC resonant converter adopting boost PWM control scheme for hold-up state operation," IEEE Trans. Power Electron., vol. 29, no. 2, pp. 841-850, Feb. 2014.

[24] M. K. Kazimierczuk and D. Czarkowski, Resonant Power Converters. New York, NY, USA: Wiley, 1995.

[25] A. Momeneh, M. Castilla, F. Van Der Pijl, M. Moradi, and J. Torres, "New inductive contactless energy transfer system for residential distribution networks with multiple mobile loads," in Proc. Eur. Conf. Power Electron. Appl., Sep. 2015, pp. 1-10.

[26] A. P. Hu, G. A. Covic, and J. T. Boys, "Direct ZVS start-up of a current fed resonant inverter," IEEE Trans. Power Electron., vol. 21, no. 3, pp. 809-812, May 2006.

[27] A. Namadmalan and J. S. Moghani, "Self-oscillating switching technique for current source parallel resonant induction heating systems," J. Power Electron., vol. 12, no. 6, pp. 851-858, Nov. 2012.

[28] A. Namadmalan and J. S. Moghani, "Tunable self-oscillating switching technique for current source induction heating systems," IEEE Trans. Power Electron., vol. 61, no. 5, pp. 2556-2563, May 2014

[29] A. Namadmalan, "Bidirectional current fed resonant inverter for contactless energy transfer systems," IEEE Trans. Ind. Electron., vol. 62, no. 1, pp. 238-245, Jan. 2015

[30] H. Koizumi, "A delta-sigma modulated class-D current-source resonant boost converter," in Proc. Annu. meeting IEEE Ind. Electron. Soc., 2010, pp. 269-273.

[31] M. Castilla, L. García de Vicuña, M. Lopez, and J. Font, "A sliding mode controller for the current-source parallel-resonant converter with zero-voltage switching," in Proc. Annu. Meeting IEEE Ind. Electron. Soc., 1997, pp. 477-482.

[32] M. Castilla, L. García de Vicuña, M. Lopez, and V. Barcons, “An averaged large-signal modeling method for resonant converters," in Proc. Annu. Meeting IEEE Ind. Electron. Soc., 1997, pp. 447-452.

[33] M. Castilla, L. García de Vicuña, J. M. Guerrero, J. Matas, and J. Miret, "Sliding-mode control of quantum series-parallel resonant converters via input-output linearization," IEEE Trans. Ind. Electron., vol. 52, no. 2, pp. 566-575, Apr. 2005.

[34] J. L. Sosa, M. Castilla, J. Miret, L. García de Vicuña, and L. S. Moreno, "Sliding-mode input-output linearization controller for the DC/DC ZVS CLL-T resonant converter," IEEE Trans. Ind. Electron., vol. 59, no. 3, pp. 1554-1564, Mar. 2012.
[35] L. García de Vicuña, M. Castilla, J. Miret, J. Matas, and J. M. Guerrero, "Sliding-mode control for a single-phase AC/AC quantum resonan converter," IEEE Trans. Ind. Electron., vol. 56, no. 9, pp. 3496-3504, Sep. 2009

[36] R. W. Erikson and D. Maksimovic, Fundamentals of Power Electronics. New York, NY, USA: Kluwer, 2004.

[37] J. L. Sosa, M. Castilla, J. Miret, L. García de Vicuña, and J. Matas, "Modeling and performance analysis of the DC/DC series-paralle resonant converter operating with discrete self-sustained phase-shift modulation technique," IEEE Trans. Ind. Electron., vol. 56, no. 3, pp. 697-705, Mar. 2009

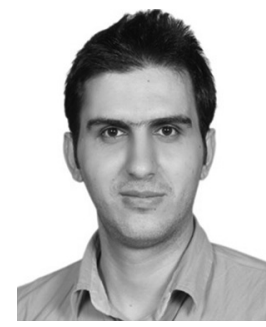

Mohammad Moradi Ghahderijani was born in Ghahderijan, Iran, in 1986. He received the M.S. degree in electrical engineering from the University of Sistan and Baluchestan, Zahedan, Iran, in 2012. Since 2014, he has been working toward the Ph.D. degree in electronic engineering a the Technical University of Catalonia, Barcelona Spain.

In 2013, he joined the Isfahan Regional Electric Company, Isfahan, Iran. His research interests include power electronics, control, and renewable energy-based microgrids.

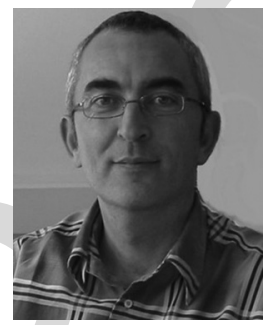

Miguel Castilla received the B.S., M.S., and Ph.D. degrees in telecommunication engineering from the Technical University of Catalonia Barcelona, Spain, in 1988, 1995, and 1998, respectively.

Since 2002, he has been an Associate Professor with the Department of Electronic Engineering, Technical University of Catalonia where he teaches courses on analog circuits and power electronics. His research interests include power electronics, nonlinear control, and renew-

able energy systems.

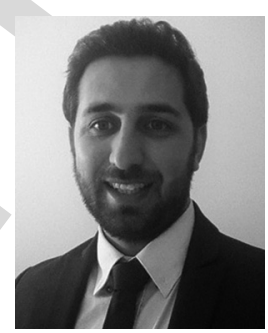

Arash Momeneh received the M.S. degree in electronic engineering from Razi University, Kermanshah, Iran, in 2010, and the Ph.D. degree in power electronic engineering from the Technical University of Catalonia, Barcelona, Spain, in 2016.

$\mathrm{He}$ is currently with the Applus IDIADA Company, Tarragona, Spain. His research interests include power electronics, electric vehicles, and renewable energy systems.

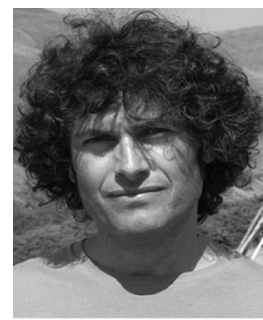

Jaume Tomas Miret (M'98) received the B.S degree in telecommunications, the M.S. degree in electronics, and the Ph.D. degree in electronics from the Technical University of Catalonia Barcelona, Spain, in 1992, 1999, and 2005, respectively.

From 1993 to 2011, he was an Assistant Professor with the Department of Electronic Engineering, Technical University of Catalonia. Since 2011, he has been an Associate Professor at the Technical University of Catalonia, where he teaches courses on digital design and circuit theory. His research interests include dc-to-ac converters, active power filters, and digital control.

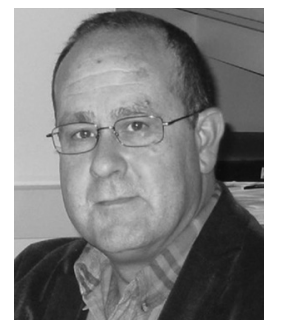

Luis Garcia de Vicuña received the M.S. and $\mathrm{Ph} . \mathrm{D}$. degrees in telecommunication engineering from the Technical University of Catalonia Barcelona, Spain, in 1980 and 1990, respectively, and the Ph.D. degree in electrical engineering from Paul Sabatier University, Toulouse, France, in 1992

From 1980 to 1982, he was an Engineer with a control applications company in Spain. He is currently a Full Professor in the Department of Electronic Engineering, Technical University of Catalonia, where he teaches courses on power electronics. His research interests include power electronics modeling, simulation and control, active power filtering, and high-power-factor ac/dc conversion. 


\section{Queries}

719 Q1. Author: Please provide the expansion of "RS" at its first occurrence in the text. 